\title{
Experience wears the trousers: exploring gender and attitude to financial risk
}

Article

Accepted Version

Creative Commons: Attribution-Noncommercial-No Derivative Works 4.0

Brooks, C., Sangiorgi, I., Hillenbrand, C. and Money, K. (2019) Experience wears the trousers: exploring gender and attitude to financial risk. Journal of Economic Behavior \& Organization, 163. pp. 483-515. ISSN 0167-2681 doi:

https://doi.org/10.1016/j.jebo.2019.04.026 Available at https://centaur.reading.ac.uk/83502/

It is advisable to refer to the publisher's version if you intend to cite from the work. See Guidance on citing.

To link to this article DOI: http://dx.doi.org/10.1016/j.jebo.2019.04.026

Publisher: Elsevier

All outputs in CentAUR are protected by Intellectual Property Rights law, including copyright law. Copyright and IPR is retained by the creators or other copyright holders. Terms and conditions for use of this material are defined in the End User Agreement.

\section{www.reading.ac.uk/centaur}

\section{CentAUR}

Central Archive at the University of Reading 
Reading's research outputs online 


\author{
Experience wears the trousers: exploring gender \\ and attitude to financial risk \\ Chris Brooks* \\ ICMA Centre, Henley Business School \\ Ivan Sangiorgi \\ ICMA Centre, Henley Business School \\ Carola Hillenbrand \\ John Madejski Centre for Reputation, Henley Business School \\ Kevin Money \\ John Madejski Centre for Reputation, Henley Business School
}

March 2019

\begin{abstract}
Are men more tolerant of investment risk than women, and if so, why? In this paper we examine gender differences in attitudes to financial risk using a very large database of questionnaires completed in the context of real investment decisions. We find that men are more financially risk tolerant than women, but this difference cannot be explained by differences in age, employment patterns or by the effect of being inversus out-of-work. We do, however, find that previous investment experience plays a significant explanatory role. We also observe that, following discussion with a financial advisor, the riskiness of the investment products selected by women are modified to a greater extent from their revealed risk preferences than those of men. We also find that where the risk tolerances of wives and husbands differ when they visit an advisor together, the preferences of the man have a stronger effect on the finally selected joint product when the wife is more risk tolerant than her husband, where she has a lower status job, or where she has less financial experience. Our research provides new evidence on the reasons why women take less financial risk than men and on the outcomes that result when men and women interact in a decisionmaking process.
\end{abstract}

Keywords: retail investors, risk tolerance, risk aversion, attitude to risk, gender, financial advisor. J.E.L. Classifications: G11, G20, J14, C25

Corresponding author: Chris Brooks, ICMA Centre, Henley Business School, University of Reading, Whiteknights, Reading RG6 6BA, UK; tel: (+44) 118378 7809; e-mail: C.Brooks@reading.ac.uk

Acknowledgements: We are grateful to the ESRC for funding this research under grant number ES/P000657/1. We thank Distribution Technology for supplying the data used in this paper. Very useful comments on a previous version of this paper were provided by Adrian Bell, Mike Clements, Tony Moore and Lisa Schopohl. We are also grateful to participants at the following seminars and conferences for their valuable feedback: Behavioural Finance Working Group, Queen Mary, London; ICMA Centre, University of Reading; Kent Business School, University of Kent at Canterbury; Smurfit Business School, University College Dublin. 


\section{Introduction}

Men are more risk tolerant than women. This observation appears to be pervasive in the literature across a range of both financial and non-financial domains (Felton et al., 2003; Weber et al., 2002). ${ }^{1}$ For example, in the driving context, men are more likely to jump an amber light and less likely to wear seatbelts (Konecni et al., 1976; Waldron et al., 2005). Dohmen et al. (2011) provide evidence from a large German household panel survey which they validate with a lab-based experiment, finding that women are significantly less risk tolerant than men in all domains (driving, personal finance, sports, career, health). This result holds even after accounting for a range of control variables such as marital status, dependents, employment category, and wealth, although the difference reduces with age. Meta-studies, which combine the findings from many previous pieces of research, have similarly concluded that women are significantly more risk averse (e.g., Byrnes et al., 1999).

Likewise, specifically within the financial context, the finding that women are more risk averse than men appears universal, and we have not found a single study strongly suggesting the reverse. ${ }^{2}$ The seminal study by Grable and Lytton (1999) showed women to adopt less risky investment strategies than men, a result strongly echoed in slew of more recent research (e.g., Charness and Gneezy, 2012). Female retail investors have been seen to invest a lower percentage of their wealth into the relatively riskier asset classes (Bernasek and Schwiff, 2001; Chow and Riley, 1992; Jianakoplos and Bernasek, 1998). The latter study also finds that the usually observed increase in risk tolerance with wealth is smaller for women. In addition, women's risk tolerances take longer to recover from an economic shock than men's (Browne et al., 2015). ${ }^{3}$

Investigating US investors born between 1946 and 1964 (the so-called "baby boomers") and using a range of control variables including age, educational level, income, wealth and marital status, Gilliam et al. (2010) show that women are more risk averse than men when completing financial attitude to risk questionnaires, corroborating the earlier result of Hallahan et al. (2004) found using a similar psychometric questionnaire applied to Australian investors. There is also evidence that men are more ambiguity averse than women (i.e.

\footnotetext{
${ }^{1}$ See Bajtelsmit and Bernasek (1996) for an early literature survey on gender differences in investment behaviour, Byrnes et al. (1999) for a review of the literature on the reduced risk tolerance of women compared with men, Corson and Gneezy (2009) for a more recent review of research on differences in risk preferences, and Eckel and Grossman (2008) for a review of the experimental evidence.

${ }^{2}$ There is, however, some research suggesting no systematic link between gender and attitude to risk (e.g., Embrey and Fox, 1997). Moreover, Schubert et al. (1999) caution that a slight nuance may be required since they find the difference in risk tolerance between men and women to be significant only in abstract gambles.

${ }^{3}$ There is also an ethnicity effect, since white males have been shown to typically be more risk tolerant in numerous domains than other groups, termed the 'white male effect', even after controlling for other variables such as education levels or incomes (Kahan et al., 2007). This joint effect has been argued to support a socio-political rather than biological explanation (Finucane et al., 2000). Flynn et al. (1994) find that in the context of environmental health, non-white men and women exhibited the same risk attitudes and perceptions, and it was indeed the white men that were outliers in believing risks to be more modest and bearable than any other group.
} 
the former have a greater dislike for outcomes that are unclear), although this is a separate feature to risk aversion (Borghans et al., 2009).

Women are relatively more concerned about losses than men (Olsen and Cox, 2001); however, by contrast it has been suggested that female Italian fund managers are more willing than their male colleagues to take risks when they have been performing below their benchmarks close to a reporting date, even though the former are more risk averse in the domain of gains (Beckmann et al., 2011). This corroborates earlier research suggesting that men are more risk tolerant than women when lotteries are framed as gains, while the reverse pattern emerges when lotteries are framed as losses (Schubert et al., 1999).

Weber et al. (2002) suggest that not only do risk tolerances differ systematically between men and women, but so do their perceptions of the potential benefits of taking risks and the level of danger involved. Hence a possible explanation of lower risk taking among women is that in the context of financial investment they are less optimistic than men, and are therefore more likely to conclude that available risk premia are insufficient and so more inclined to withdraw from risky assets when hit with negative information (Felton et al., 2003). Jacobsen et al. (2014) find based on surveys that indeed women are more pessimistic than men about future stock market performance, and this can, when combined with other control variables, explain the observed differences in their relative proportions of stock holdings. This result is echoed by Harris et al. (2006), who show that, across several contexts, women estimate higher probabilities of negative outcomes and expect to enjoy positive outcomes less. The greater degree of pessimism among female investors appears to manifest itself in their underestimation of the probabilities of large gains (Fehr-Duda et al., 2006).

What is less clear is whether gender variation in financial risk tolerance arises primarily from nature (hormonal differences) or nurture (men socialised from an early age to engage in riskier behaviour). Within the former category of explanations, Zuckerman (1994) observes women to usually have higher levels of the enzyme monoamine oxidase, which supresses sensation seeking, while the greater presence of testosterone, the strongest sex hormone, is correlated with aggressive and risk-taking behaviour (see, e.g., Apicella et al., 2008). For example, women with higher levels of testosterone were more risk tolerant than women with lower levels (Stenstrom et al., 2011), although no effect was noticeable among men (Sapienza et al., 2009). Greater exposure to pre-natal testosterone is correlated with heightened financial risk taking and greater trading activity later in life (Cronqvist et al., 2016).

There is suggestion in the neuroeconomics literature that attitudes to risk are genetically predisposed to some degree (Guo et al., 2010; Thompson et al., 2007). Buss (1999) and Wilson and Daly (1985) suggest that evolution has led to a diminished preference for risks among women as a result of their typical role as the primary carer for children and a greater perception of the risks involved in various activities makes women more effective carers for offspring (Harris et al., 2006). 
As well as cognitive differences between men and women that may affect financial decision making, some research has investigated the possible role of emotions. The literature suggests that knee-jerk emotional reactions can often have more explanatory power for decisions made than slower more deliberative thinking (Loewenstein et al., 2001). There is a broad literature documenting that women worry more than men and experience emotions more strongly in a variety of situations (McCann et al, 1991; Ricciardi, 2008). Women experience greater nervousness of possible negative outcomes (Fujita et al., 1991). In the face of such potential bad outcomes, women tend to become frightened while men become angry (Grossman and Wood, 1993). Fear as an emotional state discourages risk-taking while anger is more likely to encourage it (Lerner et al., 2003). Craske (2003) reports that women are more likely to "engage in negative self-focus", affecting mood and mental well-being. Stevenson and Wolfers (2007) highlight the lower level and relative decline of happiness among women relating to a higher tendency for self-blame in the face of bad situations.

On the other hand, in the nurture category of explanations for gender differences in risk tolerance, there is suggestion in the literature that girls are socialised into what are perceived as societally acceptable roles from a very early age, and these include being more cautious, less competitive and less aggressive (Beyer and Bowden, 1997; Slovic, 1966). Experimental results in Booth and Nolan (2012) reveal that girls in singlesex schools are equally as likely as boys from either single-sex or mixed gender schools to choose a risky gamble, whereas girls from mixed schools were more risk averse. Relatedly, the literature suggests that in Western societies, women are less confident than men in numerous situations. This additional risk taking by men is, however, not always financially beneficial. Barber and Odean (2001) find that male retail investors using an on-line brokerage account in the US trade more frequently than women, resulting in net returns being reduced by around one percentage point more per year than those of women. They attribute this finding to men being more overconfident in expecting their trades to time the market successfully, and they dismiss the alternative explanation that the additional trading is for pleasure.

Moreover, in most situations, women do not like to compete and are worse at it than men (see Gneezy et al., 2009). ${ }^{4}$ In mixed gender contests, women are less effective than men even when their performance is comparable in non-competitive environments (Gneezy et al., 2009). ${ }^{5}$ Niederle and Vesterlund (2007) find that men select a competitive tournament-style reward scheme over a non-competitive fixed rate $73 \%$ of the time while the figure for women is less than half that (35\%). One possible explanation of this finding is that men and women interpret the same performance data differently, so that women are more self-critical and more pessimistic about future performance for a given level of past performance and so their selfperceived expectation of the outcome is worse than it is actually likely to be.

\footnotetext{
${ }^{4}$ However, in matriarchal societies, women are more competitive than men, lending further support to the importance of cultural norms in determining risk preferences and behaviour (Gneezy et al., 2009).

${ }^{5}$ Interestingly, the authors observe this not to be the case in gender-separated tournaments. They find that these effects cannot be explained according to differing perceptions of the uncertainty of the payment.
} 
Turning to an entirely different strand of explanations, women may exhibit lower risk tolerance because of a lower level of financial education or less experience of risky investing, and Dwyer et al. (2002) suggest that differences in financial knowledge can partially explain variations in risk tolerance. There is evidence that a greater sensitisation to risk is linked with a reduced perception of its intensity (Slovic et al., 2000). Lusardi and Mitchell (2008) conduct a survey as part of a health and retirement survey in 2004, finding that women in the US exhibited low levels of financial literacy and most had made no financial plans for their retirement. ${ }^{6}$ Almenberg and Dreber (2015) employ a survey in Sweden and show that women demonstrate lower levels of basic financial literacy (which they classify as being represented by numeracy) and this can partly explain their lower stock market participation. Dwyer et al. (2002) argue that women exhibit lower levels of financial knowledge and this explains a significant part of the gender disparity in the propensity to take risks in the context of mutual fund investments. Other studies also suggest that gender differences in attitude to risk are related to the lower levels of financial knowledge among women (Agnew et al., 2008; Lusardi and Mitchell, 2009; Van Rooij et al., 2011). Bannier and Neubert (2016) find, using German survey data, that highly financially literate women investing in sophisticated financial instruments are no less risk tolerant than men in the same category. Using a large Finnish survey sample, Halko et al. (2012) find that the gender gap in risk tolerance remains significant after controlling for investment knowledge and education. However, stock market participation is not significantly affected by the gender gap in risk tolerance when financial literacy is also included.

However, counteracting the suggestion in the above literature that women's fear of risk may result from a low level of domain-specific knowledge, this phenomenon persists even among scientists who are highly educated and have a high level of understanding of the situation and possible outcomes (Slovic et al., 1997). For example, a study by Barke et al. (1997) finds that women scientists in the US evaluate nuclear technologies as being riskier than the assessments made by their male counterparts.

It is clear from the discussion above that while there is a strong consensus for women being less risk tolerant than men in the financial domain, there is much less agreement as to the causes. Moreover, while the survey literature on attitude to risk is voluminous and apparently conclusive, what is less clear is the magnitude of these gender differences in the real-world context. It is not obvious a priori that results from hypothetical settings where nothing is at stake will replicate the outcomes that would arise when investors are making key decisions about how to invest their pension savings. Using a unique database comprising the expressed attitude to risk and demographic information of more than half a million male and female clients visiting their financial advisors, we are able to shed important new light on this issue and to make several novel

\footnotetext{
${ }^{6}$ The study only conducted the investigation in the context of women so provided no comparative data on the literacy and behaviour of men.
} 
contributions to the literature. We investigate the impact of gender on risk tolerance after accounting for age, financial experience, wealth, marital status and employment roles as possible explanatory factors. We find that women on average have lower (self-assessed) levels of investment experience, and this is the most important factor in explaining gender differences in financial risk tolerance: the roles for differences in average age, marital status and employment are much more modest. ${ }^{7}$

We are also the first to investigate whether the client's gender affects the extent to which, following the meeting with the advisor, the actual risk of the investment product selected differs from the client's revealed risk preferences. This situation arises when the advisor combines the attitude to risk score with a host of other information to make an investment proposition that may have a different risk rating than that arising from the attitude to risk (ATR) questionnaire responses alone. For example, does a stereotype that women are more risk averse mean that they end up with lower risk financial products than otherwise equivalent men who have an identical attitude to risk? The adjustment takes place following a discussion rather than the application of a formula and therefore there is scope for the nature of the interaction to affect the outcome. We show that the ATR scores for women are subject to greater adjustments when arriving at the final selected investment products compared with those of men - both when the women are more risk tolerant and when they are highly risk averse.

Finally, we also examine the factors affecting the joint outcome when a man and a woman with different individual risk tolerances select a joint investment product and thus one or both of the partners must make a compromise. Thus we are able to shed light on who 'wears the trousers' in joint marital investment decision-making. Lyons et al. (2008) suggest that financial decisions which are made at the household level do not originate from a unified approach to making choices, but rather arise from a power struggle where differences in preferences are reconciled via an implicit or explicit bargaining system (see also Elder and Rudolph, 2003). ${ }^{8}$ Typically, models that try to capture this process assume that the partner with more bargaining power will have a stronger influence on the overall outcome of the decision. For example, it might be expectable that the partner with the more senior or prestigious employment role, the higher level of income and/or wealth, the higher level of education, and the greater level of investment experience, would hold the balance of power and would be more assertive in decision-making. Indeed, Bernasek and Batjelsmit (2002) find that women tend to be more heavily involved in household financial decisions when their share of the home's total income is greater. Similarly, Addoum, Kung and Morales (2016) show that individual income shocks induce the spouses to renegotiate their relative bargaining power in the decision-making

\footnotetext{
${ }^{7}$ At first sight, it might appear that a self-assessment of investment experience is weaker than a more objective actual measure. However, we would argue that in the context that we are interested in, the perception is likely to be more important than the reality in affecting confidence and therefore risk tolerance.

${ }^{8}$ Interestingly, Addoum (2017) shows that couples' portfolio reallocations to lower risk at retirement are greater when the husband is more risk tolerant than his wife, perhaps suggesting that women wield increasing power in household decision-making as couples age.
} 
process of the couples, and that changes in relative income are associated with reallocations in household portfolios. However, Gilliam et al. (2010) do not uncover a place for assertiveness in determining couples' joint risk tolerances and Hana and Lindamood (2005) find several contradictions from the outcomes that bargaining theory would predict. They hypothesise that when the wife in a marriage is younger, less well educated, earns less or is in poorer health than her husband, she will be more inclined to take her husband's risk appetite into account when she is revealing her risk preferences and she will have less influence on her husband's choices. Using data on the disaggregated wealth of the entire Swedish population, Thörnqvist and Vardardottir (2014) show that the decision-making power of female spouses negatively relates to the share of wealth allocated by couples to risky investments. Also related to our analysis, Ke (2017) documents that participation in the stock market is more probable when the husband is 'financially sophisticated' than the case when the wife is. He hypothesises that gender identity norms constrain women's influence on the couple's financial decision-making process. ${ }^{9}$

We are the first, aside from Thörnqvist and Vardardottir (2014), to be able to consider these issues in the real-world context, and we observe that the wife's preferences are more likely to prevail when she is the less risk tolerant of the two parties, when she has the relatively more senior/prestigious employment role and the higher her relative level of investment experience. Our finding that previous investment experience and interactions between clients and advisors, and between wives and husbands play important roles are at first sight suggestive of the dominance of nurture over nature in explaining gender differences risk tolerance. However, we are unable to rule out the alternative explanation that hormonally driven differences (e.g. men being inherently more confident and assertive) are the cause.

The remainder of this paper is organised as follows. Section 2 describes the nature of the database that we employ for this project and presents the analytical models that we estimate. Section 3 presents the core results on the interaction between gender and financial risk tolerance, while Section 4 continues to investigate the impact of client gender on the difference between the risk preference of the client and the risk level of the final investment product selected. Section 5 considers the extent to which the risk level of the product more closely reflects the preferences of the male or female partner in situations when the two differ and finally, Section 6 summarises and draws out the implications of our findings for the advisory process and for the likely investment performances of men's and women's portfolios.

\footnotetext{
${ }^{9}$ However, his definition of sophistication (or not) is based on whether an individual works in the financial services sector, a screen that would exclude the vast majority of retail investors, and which may not capture possible systematic differences in the nature and the level of employment (e.g., clerical versus executive) between men and women.
} 


\section{Data and Methodology}

\subsection{The Advisory Setting}

This paper utilises a dataset that is much bigger than those used in existing studies and represents the outcomes of real financial decisions. By contrast, the vast majority of existing research in this area takes place within the arena of lab-based experiments or general surveys which may suffer from a "hypothetical bias" where respondents take the exercise less seriously since there are no (or trivial) adverse consequences from making an inappropriate decision. Most experiments are conducted in the context of university students (e.g., Anbar and Eker, 2010), whereas those making financial decisions are typically much older (the median age in our sample, discussed below, is 58) and have worked for many years. The data that we observe are from the real-world context where clients are making financial decisions that will have consequences for the future values of their savings and their future incomes. Our sample is many times larger than anything available in the existing literature, comprising the responses to over half a million attitude to risk questionnaires.

The database is obtained from a provider of financial planning solutions based in the UK, Distribution Technology (DT). Their 'Dynamic Planner' software is used by large numbers of independent financial advisors (IFAs), via whom many retail investors make financial decisions. As part of this process, the client usually completes a risk profiling (also known as an ATR) questionnaire in conjunction with a discussion between them and the financial advisor to ascertain the client's characteristics, lifestyle, level of wealth and salary, life expectancy and future investment goals.

The database includes information on the outcomes of meetings between over 4,000 advisors and their clients. These advisors are spread across hundreds of firms including both large networks and nationals to regional and local firms across the UK. Clients will in most cases use a financial advisor based locally to them - either based on a largely random search or through a recommendation from a friend or family member. But it is a regulatory requirement that all advisors offer products from many different product providers and for all risk appetites. It is important to note that the focus of our study is squarely on the client, and not the advisor. Ultimately, if the process is working adequately, the end result should be the same whichever advisor the client uses as it is a regulatory stipulation that the former is there only to offer advice and recommendations, and should not make choices for the client, or even steer them in a particular direction against their wishes. Following the retail distribution review (RDR) in the UK, it is a further regulatory requirement that financial advisors must be remunerated via fixed fees and not via commissions on the products that they sell. Therefore, there is no incentive for advisors to encourage their clients to purchase more risky investments than the latter desire. The only incentive that the advisor has is to offer a good level of service to the client, and to provide the products that best match their risk appetite, capacity to take risk, 
circumstances, lifestyle and aspirations etc. Doing anything else could lead either to legal action or to unhappy clients who would not recommend the advisor, reducing their future level of business.

Two versions of the questionnaire to assess ATR are supplied as part of Dynamic Planner, with 10 and 20 questions. The advisor selects which to use, and approximately the same numbers of each version are completed. Currently, over 2,000 clients per week go through this process. Our sample size is growing over time for two reasons - first, the number of people seeking financial advice has grown substantially along with new pensions freedoms which UK citizens now have to withdraw and self-invest their entire pot and perceptions of the increasing complexity of the financial environment and the bewildering array of products available. Second, the company through which we obtain the data is a market-leader and has been highly successful, growing its business to the extent that its systems are now used by around a quarter of all advisors in the UK. Geographically, the sample covers the entire UK and while the numbers have grown substantially over the sample period, we believe, following discussions with the company and with financial advisors, that the data are relatively homogeneous and representative of the UK population of people seeking financial advice.

The 10 or 20 questions are individually scored on a five-point Likert scale from 'Strongly Disagree' through 'Neither Agree nor Disagree' to 'Strongly Agree'. An aggregate integer result from 1 (lowest level of risk tolerance) to 10 (highest possible risk tolerance), which we term the 'calculated ATR score', is then formed by summing the scores from the individual questions. The ATR score can only be interpreted as providing an ordinal measure of financial risk tolerance. So we can say that someone with an ATR score of 4 is more risk tolerant than someone with a score of 2 but we cannot make any quantitative judgements about how much more risk the former is willing to take than the latter. Each ATR level from 1 to 10 maps onto a portfolio with a different level of risk within fixed bands. For a given ATR level, the candidate assets are combined in an optimised way (i.e., they are chosen and their weights selected so as to provide maximum expected return for the given level of risk). The lower risk portfolios (1 to 3) mainly comprise cash and government bonds while those at the other end ( 8 to 10 ) are mainly emerging market equities.

These calculated scores will then be combined with other information including evaluations of the client's investment experience, their financial capacity to bear losses, their investment horizon, and whether the client may need access to the money to cover unforeseen circumstances. The financial advisor will blend information from these additional questions and a wider general discussion with the client to arrive at a final integer number on the 1-10 scale, which is termed the 'selected ATR score'. This selected ATR score is usually the same or slightly lower than the calculated value arising directly from the calculated ATR, and is used to 
propose investment products with a commensurate level of risk..$^{10}$ It is very much at the advisor's discretion how the final selected ATR score is arrived at. The calculated ATR score will be a key input, along with capacity to take risk (i.e., how much risk the client can afford to take without significantly adversely affecting their lifestyle if they were to face investment losses), plus their personal circumstances, dependents, their level of financial ambition and goals etc.; this is largely a qualitative judgement.

It is a requirement of DT's system that clients' completed ATRs, capacity responses, age and gender are recorded on-line. Other information, such as the client's investable wealth, employment status, health status, etc. may also optionally be recorded onto Dynamic Planner, or might be captured off-line by the advisor and so our observation of these additional demographics is less complete, albeit the numbers of data points available (tens or hundreds of thousands) are nonetheless still very large. ${ }^{11}$

We apply several filters to the raw data. Firstly, we consider only investors aged between 18 years and 100 years and drop a small number of clients $\left(0.87 \%{ }^{12}\right.$ of the original dataset) with ages outside this range. Secondly, we discard around $4.74 \%(31,758)$ of the original observations to account for those clients who answer more than $60 \%$ of questions with a middle answer (three-points on a five-point Likert scale). This threshold is adopted by DT as market practice to indicate clients having a lack of engagement with or a misunderstanding of the questions. We drop these responses, since they might not be useful for measuring their attitude to risk.

\subsection{Data Summary}

Table 1 and Figure 1 present summary statistics for the database, with a specific focus on separation of the risk score by gender. Unless otherwise stated, our focus is on the calculated ATR, since it is this that most closely captures the client's own innate risk tolerance before formal consideration of their wider financial circumstances. Panel A of Table 1 shows the total sample size of 533,518 observations splits into roughly $40 \%$ women and $60 \%$ men. The mean ATR score is 5.054 for women and 5.554 for men, confirming the key result from the literature that (before applying any controls), men are more risk tolerant than women.

[Insert Table 1 and Figure 1 about here]

Panel B shows the number of completed questionnaires and the average calculated ATR by ten-year age bands. The percentage of female clients is increasing in age, likely due to their greater longevity: they

\footnotetext{
${ }^{10}$ Sometimes, however, the selected ATR can be higher than the calculated value. The calculated ATR is smaller than the selected ATR for $6.23 \%$ of clients in our data. For $72.36 \%$ of clients, the vast majority of investors, the calculated ATR is the same as selected ATR score, while $21.40 \%$ of times the calculated ATR is higher than the selected ATR.

${ }^{11}$ We have no reason to believe that there is any selection bias in the reporting of these additional characteristics (e.g. the advisor only reports them for higher value clients) but this may exist as a possibility.

${ }^{12}$ There is a high chance that such entries would be either erroneous or represent cases where advisors are testing the system with 'dummy clients'.
} 
represent only $40 \%$ of the under 30 -year old sample, but $56 \%$ of over 80 s. This situation may also arise due to women attaining a level of wealth making it worthwhile to see a financial advisor later in life than for men.

Risk tolerance rises slightly from age $<30$ to 39 but declines almost monotonically thereafter for both men and women. The spread in risk tolerance of men over women is continually declining in age from age 30 as men become more risk averse at a faster rate than women, although men are nonetheless significantly (at the $1 \%$ level) more risk tolerant than women at all ages. Panel C shows Spearman's correlations for the whole sample and split by gender between the main variables of interest, namely the Calculated ATR score, age, capacity, time and liquidity (likelihood that the client will need access to the funds to cover unforeseen circumstances). ${ }^{13}$ Almost all correlations are significant at the $1 \%$ level except for the pairs age and liquidity (All), and age and capacity (Female). As expected, the Calculated ATR is negatively correlated with age ($22.76 \%$ for all clients), and positively correlated with the capacity questions: $38.54 \%$ with capacity to bear losses, $19.22 \%$ with investment time horizon, and $9.16 \%$ with liquidity for all observations. Additionally, age is negatively correlated with capacity and time (all observations). However, the correlation between liquidity and age is small. Overall, the correlations between Calculated ATR and the other variables are marginally higher in absolute terms for male than female investors.

Figure 1 focuses on the calculated ATR for men and uses a larger scale so that differences can be discerned. It is clear that the temporal profiles for men (blue line) and women (red line) follow approximately the same patterns - both, for example, falling from their March 2012 peak to October of that year and then rising again thereafter. Hence, the calculated ATR for all clients is fairly stable over time, and the risk tolerance of men is higher than that of women for every sample month. ${ }^{14}$ However, what is also noticeable in Figure 1 is that the spread between the two lines is narrowing over time. This appears to arise predominantly due to women growing slightly more risk tolerant over time rather than men becoming less so. The black line (right-hand scale) plots this spread over time, along with its linear trend (feint black line). Extrapolating this trend forwards, at this rate the spread would become zero by April 2030, just over 13 years from the end of our sample period, so at that date men and women are predicted to become equally risk tolerant. ${ }^{15}$ One possible partial explanation is that the average age of women in the sample is increasing less quickly than that of men, and the figures in Panel B of Table 1 demonstrate that financial risk tolerance declines with age (see, for example, Bommier and Rochet, 2006, Dohmen et al., 2011; Jianakoplos and Bernasek, 2006 or Brooks et al., 2018 , among many others for evidence on this issue). An alternative explanation is that women have reacted differently to the changing macroeconomic and financial backdrop than men - for instance the former may have been less affected than the latter by the aftermath of the financial crisis and the impending Eurozone

\footnotetext{
${ }^{13}$ Section 2.3 provides details on the definition and measurement of the main variables.

${ }^{14}$ Note that we are not tracking a single set of respondents over time but the very large sample size ought to imply that their overall characteristics are fairly constant over a six-year period.

${ }^{15}$ Given the relatively short length of the six-year sample, we recognise of course that the standard errors around this extrapolation are very large.
} 
problems in 2011. A final potential explanation is that over time, women have begun to adopt traditionally male behaviour traits regarding other domains of risk-taking behaviour. This has been found to also be the case, for example, in alcohol consumption, where the previously large gap between the drinking patterns of men and women has diminished significantly between older and younger generations (Slade et al., 2016).

The fact that male clients are more likely to appear in higher attitude to risk categories based on their questionnaire responses is shown in Figure 2. This figure plots the surface of estimated absolute probabilities ${ }^{16}$ for each gender and for each calculated ATR. ${ }^{17}$ The probability distribution is more skewed to the right for male than for female investors. Female clients are more likely to be allocated to a Calculated ATR score equal to 5, followed by a score of 6 and 4 , and with probabilities equal to $28.65 \%, 22.37 \%$ and $21.83 \%$ respectively. Male investors are more likely to be allocated to a Calculated ATR score equal to 5 and 6 (almost equally probable), followed by a score of 7 , with probabilities specifically equal to $26.68 \%, 26.33 \%$ and $17.40 \%$ respectively.

[Insert Figure 2 about here]

The difference between male and female investors reveals clearly the impact of gender on the probability distribution of the ATR categories. On the one hand, in total $33.77 \%$ of female investors and $22.46 \%$ of male investors appear in a risk tolerance category lower than or equal to 4 . On the other hand, $15.21 \%$ of female clients and $24.53 \%$ of male clients are in a risk tolerance category greater than or equal to 7.

\subsection{Methodology}

The following analysis investigates the extent to which gender can explain the cross-sectional variation in ATR score. Since the dependent variable for these regressions ${ }^{18}$ is the calculated ATR score of investor $i$, which can only take integer values from 1 to 10 , OLS would be an inappropriate estimation technique and we therefore employ ordered probit ${ }^{19}$ in all of the following models. The core model specification is:

Prob. Calculated ATR $R_{i}=\alpha^{\prime}+\beta_{1}$ Male $_{i}+\beta_{2}$ Age $_{i}+\beta_{3}$ Age $_{i}{ }^{2}+\beta_{4}$ 10QuestionVersion $_{i}+\gamma_{i}{ }^{\prime} X_{i}+\epsilon_{i}$

where $\alpha^{\prime}$ is a vector of cut-off points estimated in ordered probit models ${ }^{20}$ (constant terms); $\epsilon_{i}$ is the i.i.d. standard normal error term; $\mathrm{Age}_{i}$ is the client's age and is measured in years (and fractions thereof), and $\mathrm{Age}_{i}^{2}$ is rescaled over 1,000 for convenience of presentation.

\footnotetext{
${ }^{16}$ The underlying model specification used to compute the probability surface is an ordered probit with robust standard errors, gender dummy, age, age ${ }^{2}$ and time fixed effects. This model is discussed in detail below.

${ }^{17}$ In unreported tables, we computed the surface for marginal probabilities with quantitatively and qualitatively similar results.

${ }^{18}$ In ordered probit models, the estimated dependent variable is a latent unobserved probability which is computed as a z-score. The probability of an ATR score $j=1,2, \ldots, 10$ is measured as the probability that the estimated regression model, plus an error term, is within a range of values (cut-off points) specific to the outcome $j$, which is the overall calculated ATR score.

${ }^{19}$ We estimate the ordered probit models using maximum likelihood.

${ }^{20}$ The estimated cut-off points are not reported for brevity.
} 
A dummy variable 10 QuestionVersion ${ }_{i}$ is included, which takes value of one when the investor completes the 10-question version of the questionnaire, and zero otherwise. More questions are likely to lead to a more accurate assessment of the client's latent, true ATR provided that he/she continues to engage with the process and questionnaire fatigue does not set in (see, for example, Forman et al., 1998, for a discussion of some of these issues). Since the net effect of reduced noise on one hand and increasing likelihood of attention deficit on the other is ambiguous, we do not specify any expected sign for this parameter. Male ${ }_{i}$ is the key variable: a dummy equal to one investor's gender is male, and zero otherwise; $X_{i}$ is a vector of additional explanatory variables which we categorise into four groups: risk financial capacity, employment category, marital status and investment experience. $X_{i}$ consists of the following variables.

\section{Proxies for risk financial capacity:}

Capacity: It is the client's financial ability to absorb losses (e.g. the client's assets could significantly fall in value without affecting his/her ability to draw the needed level of income). It is a score variable which takes values of 0,1 and 2 if the ability to absorb losses is stated to be limited (or zero), medium and large (e.g. low impact on future standard of living) respectively.

Time: It is the investment time horizon stated by the investor. It is measured as a score variable which takes values of 0,1 and 2 if the time horizon of the clients is short, medium or long. The short time horizon ranges from one to five years, the medium time horizon ranges between five to ten years, and longer time horizon is larger than ten years respectively.

Liquidity: It is the client's perception of how likely they are to need to cash in (or access) the investment in case of unexpected circumstances. We use a score variable which takes values 0,1 and 2 respectively according to whether they are more likely to need access to their funds (e.g., due to limited alternative funds), whether their liquidity needs are medium, or whether other savings could be used for most needs, and thus the investor's liquidity is high. Thus a liquidity of 0 implies that the investor is likely to need to access the investment in the event of unforeseen circumstances, and at the other extreme, a value of 2 implies that the investor is most unlikely to need access to the funds. ${ }^{21}$

\section{Proxies for employment category:}

Employment Category: It is a set of binary dummy variables which takes values of one according to the investor's employment category. The variables ${ }^{22}$ are: 1. Director or Partner, 2. Employed and Self-employed

\footnotetext{
${ }^{21}$ Note that 'liquidity' in this context refers to the other resources that the investor may have access to rather than the ease of sale of the investment under consideration.

${ }^{22}$ Employed, temporarily employed and contracted clients, and students and unemployed clients, are combined into the single categories of 'Employed' and 'Non-Working' investors.
} 
(at the same time), 3. Self-employed, 4. Employed, 5. House-person, 6. Semi-retired, 7. Non-working, 9. Retired. $^{23}$

\section{Proxies for marital status:}

Marital Status: It is a set of dummy variables which take value of one according to the marital status of the investor. The possible statuses are Single, Civil Partnership, Married, Divorced and Widowed. ${ }^{24}$

\section{Proxy for investment experience:}

Investment Experience: It is a proxy which measures both the investor's self-assessed level of experience and financial literacy when evaluating an investment opportunity. It takes values ranging from 0 to 2 according to whether the investor is not experienced and with no relevant financial literacy, whether his/her experience and knowledge of financial investments is medium, or whether the investor is comfortable with investing and has some understanding of the potential financial risks and rewards. ${ }^{25}$ The higher the investment experience, the more risk tolerant the investor is likely to be.

All models include year fixed effects to capture any general movements in risk tolerance over time. Our main interest is the effect of gender on the expected risk tolerance of the client. Thus, in the penultimate row, we calculate the difference between the risk tolerance of men and of women implied by the model, calculated by multiplying the marginal probabilities of each classification by their respective expected model-fitted attitude to risks for each. ${ }^{26}$ We additionally report the marginal probability of a Calculated ATR equal to six, ${ }^{27}$ which reflects a level of risk slightly greater than the sample median ATR - for all predictors in order to evaluate the marginal likelihood changes corresponding to one unit increases in the independent variables. ${ }^{28}$

\footnotetext{
${ }^{23}$ 'Retired' is used as the reference category.

${ }^{24}$ We select 'Single' as the base category of all marital statuses.

${ }^{25}$ We should therefore note here that the client's level of investment experience is self-assessed and there may be systematic differences in the way that clients respond to this. We shall return to this point later. The full question asked is, "Overall, how would you describe your level of investment experience? (a) Not at all experienced: I'm not very comfortable with investing; (b)

Somewhat experienced: I understand the basics but still want some things explaining; (c) Experienced: I'm comfortable with investing and have some understanding of the potential risks and rewards".

${ }^{26}$ For both male and female clients, we estimate the probabilities (margins) of a client being allocated to each of the 10 ATR scores based on the ordered probit estimation. We then compute for both genders the model fitted ATRs (expected value) by summing the products between each probability and the relative ATR score. Finally, the model fitted difference is the spread between the expected ATR score for male and female clients.

${ }^{27}$ We arbitrarily report the marginal effects of only one possible ATR score - this score corresponds to the median Calculated ATR of a young investor (see Table 1).

${ }^{28}$ When examining marginal effects for variables that are included more than once in an ordered probit model in different forms in our case the Age and $\mathrm{Age}^{2}$ and also when we include interaction terms between capacity, time and liquidity - this can result in a possible over-estimation of the distinct marginal effects each individual variable. Therefore, to avoid this issue we show the total marginal probability for Age, which includes both the effects from linear and quadratic terms and similarly for capacity, time and liquidity.
} 


\section{Results}

\subsection{Core Results on the Effect of Gender on ATR}

Table 2 presents the first set of results ${ }^{29}$ on the link between gender and risk tolerance within the ordered probit regression framework. Note that, since there are ten categories (risk levels), in the interests of brevity we report the parameter estimates rather than all sets of marginal effects for each specification. The column headed (1) includes only the Male dummy variable, which is positive and significant at the $<0.1 \%$ level, indicating that men have a significantly higher probability of being in a high risk tolerance category than women. The explanatory power from gender alone, as measured by the pseudo- $\mathrm{R}^{2}$ is just under $1 \%$, although it increases to nearer $8 \%$ when the control variables are sequentially added. ${ }^{30}$ For men, the marginal probability of an ATR equal to six is greater than for women by $3.9 \%$.

[Insert Table 2 about here]

As we move from left to right across the tables, the number of control variables increases, although the main finding of the empirical importance of gender in affecting attitude to risk remains. As we might expect given the existing literature, risk aversion increases with age, and the 10-question version dummy variable also takes a negative sign and is highly significant, suggesting that clients taking this shorter questionnaire are on average less risk tolerant (column (2)). The latter finding is interesting, and discussions with advisors using the system have not revealed any systematic factors that explain the different choices between the two. Thus the decision appears to be largely the preference of the specific advisor (or in some cases, the firm an advisor works for may have a policy which specifies a particular version). The 20-question version should lead to a more accurate assessment of risk tolerance, but takes more time to complete. Thus one possible line of explanation as to how the choice is made is that it relates to the amount of time that an advisor wishes to spend on a particular client. Advisors tend to devote more time to 'higher value' clients, who will have larger sums of money to invest and so will be charged higher fees for a more comprehensive service. There is strong evidence in the literature, which we cite in the introductory section above, that wealthier investors are on average more risk tolerant, so we think that, ultimately, wealth acts as a mediator between risk tolerance and the choice of the 10 - or 20 -item version of the questionnaire.

The client's financial capacity to bear losses has the most statistically significant effect on risk tolerance, and has the expected positive sign, so that clients who self-assess themselves as having greater financial ability to withstand losses also express a greater willingness to take risks. The interaction term between financial capacity to bear losses and gender is also positive, so that greater capacity leads the risk tolerance of men to

\footnotetext{
${ }^{29} \mathrm{Y}$-standardized coefficients are reported in all tables in order to compare estimates from different model specifications. See for instance Long and Freese (2006).

${ }^{30}$ It is worth noting that relatively low goodness of fit statistics is a feature of ordered probit models: when we use identical dependent and independent variables in an OLS framework, the $\mathrm{R}^{2}$ value is approximately two to three times larger in every case.
} 
increase by more than it does for women on average. The other two variables embodying information regarding time horizon and liquidity similarly have positive signs on both the individual terms and their interactions with the male dummy. ${ }^{31}$ For a given level of capacity, time and liquidity, male investors have marginal probability of being in the ATR 6 category higher than female investors ${ }^{32}$ (Table 2, columns (3), (5) and (7)). After controlling for all factors (Table 2, column (9)) the difference in the predicted ATR between male and female investors significantly drops from 0.4988 notches to 0.4135 notches, a decrease amounting to $17.10 \%$ of the original gender gap in the fitted Calculated ATR. The time horizon variable is particularly interesting given the additional longevity of women, which might lead us to expect that the latter would have longer expected investment periods. However, what we observe (in results unreported due to space constraints) is that overall, women are more likely to have medium-length investment horizons than men. When we separate the client sample by age, we observe that men have significantly longer horizons (on a 0 , 1,2 ordinal scale) in all age buckets up to 59 , but the sign then switches so that women have significantly longer horizons thereafter for most age groupings.

\subsection{Employment Category and ATR}

A possible explanation of gender differences in risk tolerance is that men are sensitised to taking risks as a result of their greater presence among employment categories with higher levels of responsibility. For example, Hardies et al. (2012) suggest that when women self-select into employment categories traditionally seen as male-dominated, they may be as confident and risk tolerant as men. Using a sample of students and of auditors, they find that in this context, men and women exhibit the same degree of overconfidence, but the women are still less risk tolerant than their male counterparts.

In this study, we are able to further test this conjecture in a much more realistic setting by examining the differences in financial risk tolerance among men and women who have reached positions of considerable authority and responsibility. Table 3, Panel A begins this analysis by presenting summary statistics for ATR by employment function and gender. Around 50,000 clients have provided details regarding their employment status, and the categories available are: director or partner; employed and self-employed; self-employed; employed (including contractors and temporary workers); house-person; semi-retired; non-working (i.e. unemployed or student); retired. Around three quarters of the sample are either in employment or retired, and the rows in the table are ordered by the average calculated ATR score for that grouping. As might be expected, those who have reached positions of seniority (and probably high salary) and the self-employed

\footnotetext{
${ }^{31}$ As an additional control variable, we include the client's net wealth. While this variable is statistically significant and has the expected positive sign, its inclusion does not affect the relationship between gender and risk tolerance, and nor is an interaction term between wealth and gender statistically significant. We therefore do not present these results in the interests of brevity.

all models estimated, we do not compute the marginal effects of interactions between variables and the Male dummy since they are not independent. The estimation of these marginal effects would be econometrically incorrect and it could lead to over or underestimation of the marginal effects (see Williams (2012)).
} 
are more risk tolerant than those who are house-persons, semi-retired, retired or not working. ${ }^{33}$ Interestingly, men are significantly (at the $1 \%$ level) more risk tolerant than women in all employment categories except house-persons, where they are significantly less risk tolerant, although we must note the very small number of men in this category where $94 \%$ of respondents are women.

[Insert Table 3 about here]

The employment summary statistics therefore suggest that differences in employment roles are unlikely to be key drivers of the variation in attitudes to risk between men and women - indeed, the gender differences in ATR are at their greatest for precisely those categories with significant responsibility and are lower for retired and otherwise not working. However, there are likely to be differences in the characteristics of those in each employment category - for example by age, income and wealth. Therefore, in order to more fully investigate the effect of employment on gender differences in risk tolerance, we embed dummy variables for each employment category and their interactions with gender into the ordered probit framework described above, with the results being presented in Table 4.

[Insert Table 4 about here]

We re-present the results including only the gender dummy variable and the other controls for comparison in this sub-sample. Retired clients are the reference category in this specification and so this dummy is omitted from the model. Without the interactions between employment and gender (columns (2) and (4)) and after allowing for the effect of age, compared with the retired, all other categories have significantly higher average risk tolerances (even house-persons) except for those not working. When the interaction terms are included, (columns (3) and (5)), the findings are largely unaltered but we additionally observe that men have significantly higher risk tolerance in every employment category except for house-persons, where they are significantly less risk tolerant, and non-working, where there is no statistical difference between men's and women's risk tolerance. A house-husband is $1.957 \%$ less likely to have a Calculated ATR score equal to six when the interaction terms with the Male dummy are included (column (5)). It is perhaps surprising that employed men are more risk tolerant than similarly employed women for all employment levels - one might have expected that women in high responsibility jobs, for example, would be more similar to men in this regard as a result of the career risks they take or the personality characteristics leading women to reach high responsibility jobs in a context where it is often challenging for women to reach such positions.

The difference between the predicted ATR of men versus women drops from 0.5384 (column (1)) to 0.4753 (column (3)). This decrease corresponds to $13.33 \%$ of the original gender gap in the Calculated ATR. The difference between the predicted ATR by gender after controlling for all factors is 0.4344 (column (5)). It is

\footnotetext{
${ }^{33}$ Alternatively, it could have been the case that those with jobs involving taking more risk (e.g. the self-employed) would have more volatile income streams and would therefore prefer safer investment products; however, this is not actually what we find.
} 
clear from the results in Table 4 that allowing for differences in employment patterns does little to dent the key finding that men are more financially risk tolerant than women.

\subsection{Gender, Marital Status and ATR}

An additional important facet of the link between gender and attitude to risk is its interaction with marital status. Ignoring age and gender, the literature is not entirely clear on whether married couples are more or less risk tolerant than single people (Yao and Hanna, 2005). However, within a married couple, just as single women are less willing to take financial risks than single men, wives are less risk tolerant than their husbands (Hanna and Lindamood, 2005). Yilmazer and Lyons (2010) find that the characteristics of a husband (in terms of his age and employment for example) affect his wife's financial risk tolerance level, but not the other way around. Perhaps surprisingly, they find that women are less likely to invest in risky assets when they earn the lion's share of household income. Preferences within couples are not necessarily simply an average of the two individuals: although married men are less risk tolerant than their single counterparts, women's risk tolerance does not rise upon marriage as their preferences coalesce (Yao and Hanna, 2005).

When a married person completes an attitude to risk questionnaire, it may be that they are not revealing their true, innate preferences for risk but rather a 'watered down' version of it which moves part way to that of their partner (Bernasek and Shwiff, 2001, p.346). If we find that married couples visiting a financial advisor share similar appetites for risk, there are several potential explanations. It may be that they colluded in answering the questions, that they were attracted to someone sharing similar attitudes, that they answered questions from the household perspective rather than their own, or that gradually over the time that they have been together, their attitudes and beliefs have homogenised. The literature has suggested that married couples seem to make similar investment choices (Jianakoplos et al., 2003; Uccello, 2000), but also that the choices of individuals (and the utility of those choices) can be affected by looking at the selections made by others so that they could become either less or more risky, with the extent of following the cue of others dependent on both the strengths of one's own beliefs and also how far they are away from the choices of others (Chung et al., 2015).

Married clients are also on average older than their single counterparts, and are more likely to have dependents, both of which would tend to lead to reduced risk tolerance. Table 3, Panel B reports the summary statistics for ATR by marital status and gender. The difference between the average ATR of male and female investors is higher for divorced and single individuals, followed by married, widowed and civil partnerships.

Table 5 presents the ordered probit model results on the effect of marital status (and its interaction with gender) on risk tolerance. As before, we re-report the initial regressions including only the male dummy variable (column (1)), and the controls (columns (2) to (6)) since the sub-set is different (and considerably 
larger at around 370,000 clients) than previously because more advisors post their clients' marital status data into the DT system than they do for employment. In this table, the reference category is single (both men and women) and so the effect of being in a different marital status category is measured relative singlehood. The base results in column (2) show negative and highly significant parameter estimates for the married, divorced and widowed categories, although only the latter is of a non-trivial magnitude. The marginal probability of having an ATR score of 6 is $-4.038 \%$ for widowed investors (column (2)). However, marital status tends to follow the cycle of life, so that, all else equal, single clients are likely to typically be young, married clients middle aged, and divorced and especially widowed clients older. Thus it is perhaps not surprising that the results change considerably when age is included as a control variable in column (3), so that the signs on all three categories flip to positive (although the estimates are now even smaller in magnitude) suggesting that married, divorced and widowed clients are actually no less risk tolerant than their single counterparts after allowing for their ages. After the inclusion of the marital status and control variables for age and the questionnaire version, the difference between the predicted ATR of men and women drops from 0.4790 (column (1)) to 0.4493 (column (4)), corresponding to $6.20 \%$ of the original gender gap in the Calculated ATR.

\section{[Insert Table 5 about here]}

As previously, we also incorporate terms that interact the male dummy variable with the marital status category dummies in columns (4) and (6) of Table 5. These specifications present much more mixed results, but the most salient features are the positive and highly significant estimate for divorced men and the negative and highly significant estimate for widowed men. A divorced $\operatorname{man}^{34}$ or a widowed man are more and less likely respectively to have a risk score of six than otherwise identical female clients, respectively (column (6)). It seems that divorced male investors are risk tolerant to the same extent as single male investors, while this effect is not observed for female clients. Different explanations could justify this finding. First, on the one hand male investors could perceive their changed marital status as a second "youth", experienced already when single and younger (e.g., feeling free and unbound). On the other hand, divorced female investors could be acting more rationally in not changing their attitude to risk. Secondly, there might be a difference in the way being divorced is perceived by the wider society and the couple's peers for different genders. Being a divorced female could be perceived more negatively than for male individuals, resulting in a different impact on their risk tolerances.

\subsection{Gender, Investment Experience and ATR}

A further possible explanation that has emerged in the literature for the lower financial risk tolerance of women is that they have relatively lower levels of investment experience, as discussed in Section 1 above. DT have formally asked questions concerning investment experience since February 2012 and the responses

\footnotetext{
${ }^{34}$ Incorporating other characteristics such as the number of children and their standard of living could lead to different conclusions; unfortunately, however, we have no information on dependents.
} 
to these questions suggest that men indeed have higher levels of (albeit self-assessed) financial experience. Table 6, Panel A reports summary statistics for the investment experience by gender. The variable is measured as a score which takes values from 0 to 2 according to whether the client's investment experience is limited, medium or high. Investment experience for male investors is statistically significantly higher than for female clients. Panel B reports the average Calculated ATR by gender and level of investment experience.

[Insert Table 6 about here]

The figures in Table 6 showed that, perhaps counter-intuitively, the gender gap in risk score increases with investment experience. We therefore include an investment experience composite variable in Table 7 using the sub-set of clients for whom this information was inputted into the system since that date. As expected given the summary statistics in Table 6, the male dummy variable on its own (column (1)) has a smaller magnitude than previously, reflecting the reduced difference in risk tolerance between men and women over the more recent period. When we include investment experience (columns (2) to (5)), we find that the effect of gender on attitude to risk declines considerably, suggesting that it is the case that the greater investment experience of men explains a sizeable part of their additional risk tolerance. For instance, the difference in the predicted ATR between men and women declines from 0.4204 (column (1)) to 0.2722 (column (3)), a reduction of spread equal to $35.25 \%{ }^{35}$ of the original fitted ATR spread. The marginal probability declines as well, from $3.545 \%$ to $3.035 \%$ (columns (1) and (3)). Also, the difference in the predicted ATR by gender drops from 0.4204 to 0.2671 . The interaction terms of investment experience with the male dummy (columns (3) and (5) of Table 7) are both positive and highly significant, albeit less significant and with much smaller magnitudes than the pure investment experience variable, with the marginal probability of the latter being $8.297 \%$ (column (5)). This suggests two key findings: first, risk tolerance increases with investment experience for both men and women, but second, for the former, a given improvement in their sensitisation to investment has a slightly greater effect still. The first of these results is indicative of the importance to ensure that all groups in society are given opportunities to gain investment experience, for example through simulated savings and trading exercises at school level. The latter speaks to the established result in the literature regarding the relative level of confidence of men; we will return to these implications in the concluding section. Many people find making investment choices complex; it appears as if familiarity with investment makes it appear simpler for men than the same amount of experience would for women.

[Insert Table 7 about here]

\footnotetext{
${ }^{35}$ This decrease is 2.06, 2.64 and 5.69 times greater than the decrease observed after controlling for risk financial capacity proxies, employment status and marital status, respectively. Our finding here is closely related in numerical terms to that of Halko, Kaustia and Alanko (2012), who find using Finnish data that accounting for investment knowledge reduces the difference in risk tolerance between men and women by around $30 \%$.
} 
As we discuss above, the sample sizes vary from one piece of analysis to another because advisors are only required to input the core information onto the system relating to risk tolerance (i.e., 'actual' and 'selected' ATR values) and basic demographic information. It is optional for advisors as to whether they input more specialised data, such as on employment and investment experience onto the system or not-some do, while others prefer to retain this information off-line. As a result, we lose a significant portion of the sample for some of the later tables in the paper. Therefore, in Table 8 we present the results from analysis using only the common sample that is available for every variable; this is much smaller since advisors report some variables but not others (e.g., some record marital status but not employment and other advisors do the reverse). The results are not qualitatively altered but the magnitudes change slightly and we lose some statistical significance as a result of the considerable drop in the number of observations. In particular, in column 2, our previous results hold for gender, age and the questionnaire dummy; in column 3, liquidity has the expected sign but is now not significant and the results hold for risk financial capacity; in column 4 , the employed and house person dummies are not significant, although the other results on employment are as above; and in columns 6 and 7 our core results for the impact of investment experience also still apply.

[Insert Table 8 about here]

\section{The Impact of Client Gender on their Interaction with the Advisor}

The risk level of the final selected financial product is the result of a discussion between the client and advisor in the light of the quantitative information from the ATR questionnaire and other data. In many decisionmaking contexts, the choices that women make appear to be more affected by the design than is the case for men, due to the former picking up more on 'social cues' from the experimenter and the setup about what is an appropriate course of action (Gilligan, 1982). Differences in typical risk preferences between men and women are sufficiently well known that they have become stereotyped when people are predicting the risk tolerances of others (see Siegrist et al., 2002), and some financial services companies have even developed gender-specific investment products (Barasinka and Schäfer, 2013). This is important in the advisory context since it is possible that advisors may subconsciously be inclined to recommend different (and probably lower) risk financial products to women than to men even given the same calculated attitude to risk and holding all other factors constant.

In the context where there are stereotypes and societal norms around gender and risk taking behaviour, there are incentives for people not to reveal their true preferences when completing attitude to risk questionnaires (see the social identity model of Akerlof and Karanton, 2000). This situation arises because people's true preferences are latent and we can only observe an imperfect proxy for them through the selections made. Specifically, men, knowing that the advisor expects them to be sufficiently 'macho' to take risks, may either consciously or subconsciously make responses that are consistent with more risk than he would really like to bear, while women have the opposite incentive. Barasinka and Schäfer (2013) use a multi- 
country panel of survey data from four European countries and show that women from the most genderunequal country are less likely to hold risky assets than men even when their reported risk tolerance scores are identical.

Hence it is possible that, given their relatively lower level of investment experience and advisor presumptions about gender preferences and appropriateness of risks, women may end up with a different investment product embodying a lower level of risk compared with an otherwise identical man. ${ }^{36}$ In order to investigate this, in Table 9 and Figure 3 we examine the difference between the calculated (arising directly from the questionnaire) and selected ATR scores. We present both the average actual ATR adjustment for each risk level, which may be either up (selected > calculated), null (selected = calculated), or down (selected < calculated) and the average absolute adjustment. As mentioned above and as Table 9 confirms, the average actual adjustment in ATR score between the calculated and selected ATR is down (by 0.234 notches), although it is slightly greater for men than for women when averaging across all calculated risk tolerances, with approximately the same standard deviation. In other words, compared with the result arising directly from the ATR questionnaire, the actual investment products that clients walk away with are of lower risk on average.

[Insert Table 9 and Figure 3 about here]

However, it could be that women's ATRs are subject to greater adjustments in both directions that cancel out in the average whereas men's risk tolerances are predominantly adjusted downwards and thus superficially appear bigger on average. To investigate this possibility, Panel A of Figure 3 separates out the adjustments in risk level according to the risk score of the client based on the questionnaire (calculated risk level) and this is indeed what we find. The figure shows that when the client's own preferences are for a very low level of risk ( 1 to 4 on the $x$-axis scale), women's self-assessed risk tolerances are raised by around 0.2 notches on average more than men's, while for high risk tolerances (6 to 9 on the $x$-axis), women's risk levels are on average reduced by more than those of men. Thus women's scores, be they lower or higher than typical values, are modified by a greater amount than those of men after discussion with the financial advisor.

Probing this result further, in Panel B of Table 9 (and graphically in Figure 3), we present the average ATR adjustment (both actual and absolute value) by gender for each calculated ATR score. It is clear that for the two extremes (calculated ATR of one or ten), the adjustment can only go in one direction and therefore the actual and absolute differences between the calculated and selected ATRs are the same. For all calculated risk levels except 10, women's risk preferences are modified to a greater extent than those of men. This difference is greatest for risk level 1 : in other words, when women essentially say in the ATR that they want to take no risk, they are significantly more likely to be persuaded to do so than male clients.

\footnotetext{
${ }^{36}$ Unfortunately, we do not have information on the gender of the advisor, only of the client.
} 
We therefore investigate what factors determine the ATR adjustment. In doing so, we estimate a model where the dependent variable ${ }^{37}$ is a score measure which takes values $-1,0$ and 1 according to whether the ATR adjustment is negative, null or positive. Apart from the different dependant variable, the model specification includes the same independent variables as for the core results presented in Section 3.1. We additionally create four binary variables to control for the effects of the interaction of the investors with the advisors. Male, ATR $<=4$ and Male, ATR $>=6$ are two dummy variables equal to one when the client is male and his Calculated ATR is smaller than or equal to 4 , or greater than or equal to 6 , respectively. Female, ATR $<=4$ and Female, ATR $>=6$ are two dummy variables equal to one when the client is female and her Calculated ATR is smaller than or equal to 4 , or greater than or equal to 6 , respectively. Table 10 reports regression results of the model estimated with ordered probit, robust standard errors and time fixed-effects (year). As expected, on average male investors are less likely to have a positive ATR adjustment when meeting the advisors by $1.514 \%{ }^{38}$ (column (1)). As already observed before, when including the dummies related to the advisory effect (columns (2), (4) and (5)), both male and female clients with a Calculated ATR smaller than or equal to 4 are more likely to be subject to a significant positive ATR adjustment, but with a greater probability for women than men $(6.089 \%$ and $4.837 \%$ respectively, column (2)). In cases where the investor's Calculated ATR from the questionnaire is greater than or equal to six, the ATR adjustment is less likely to be positive, with greater absolute marginal probabilities for women with respect to men $(-4.352 \%$ and $-3.792 \%$, column (2)). These results are robust to the inclusion of age, questionnaire type and general capacity questions.

[Insert Table 10 about here]

There are two potential explanations for these findings. The first is that advisors are taking into account either consciously or sub-consciously - the different behavioural biases that men and women suffer from, in order to counteract them in a benevolent way to improve the outcome for the client. The second is that advisors are employing stereotypes when evaluating information to treat otherwise identical male and female clients differently from one another. Given that women are more risk averse (and so left to their own devices would select lower risk investment portfolios) and that the result of the advisory conversation is on average to reduce the level of risk taken for all clients, it is surprising that women are subject to greater adjustments than men in the portfolios they end up with compared to their self-selected preferences. It might be the case that women are less assertive than men in defending their preferences and thus the advisor's views are given relatively more weight in the discussion than when the client is a man.

\section{When Men and Women Seeking Financial Advice Together Differ in their ATR, Who Wins?}

\footnotetext{
${ }^{37}$ Results are qualitatively similar when using the original ATR adjustment and the absolute ATR adjustment. For ease of presentation, we only report results where the sign of the ATR adjustment is used as the dependent variable.

${ }^{38}$ We report the marginal probabilities for a positive ATR adjustment.
} 
It is common for a couple to make a joint visit to a financial advisor, and in such circumstances the process is that each will fill out an individual ATR questionnaire but their preferences will then be combined to result in a single investment product with a given risk level (a so-called 'joint plan'). When the partners within a family have different ATRs, it should be very much a discussion between the couple to arrive at the collective value. It is a fundamental regulatory principle that the advisor only advises; they should not unduly influence decisions made and should definitely not make choices on behalf of clients, otherwise they risk subsequent legal action should the investments perform badly later on.

In many cases, both of the partners share a common ATR score ( $68.451 \%$ of married couples in our dataset), but in circumstances where they differ, it is necessary for the advisor to reconcile these varying preferences to arrive at a single investment outcome with a single risk level. In these cases, effectively there will be a "winner", whose own ATR score is closer to the joint outcome, and a "loser" whose individual ATR score is further away. ${ }^{39}$ When the couple comprises a man and a woman, can we identify the factors that cause one gender to be the winner rather than the other ${ }^{40}$ Panel A of Table 11 shows that for $7.603 \%$ of married couples, the wife is less risk averse than her husband, while the reverse situation occurs $23.946 \%$ of the time. Table 11 also reports the frequency of cases for which there is a winner (or not) based on the comparison between the relative Calculated ATR scores of spouses. In absolute terms, wives and husbands win about the same percentage of times (14.23\% and $14.09 \%$ respectively). However, when the woman is more risk tolerant, she wins $28.39 \%$ of the time; when the man is more risk tolerant, he wins $38.48 \%$ of the time. When the woman is more risk tolerant, the man wins $64.16 \%$ of the time; when the man is more risk tolerant, the woman wins only $50.41 \%$ of the time.

We can probe this result further by examining the expected number and percentage of cases that would occur if winning or losing were independent of whether the man or woman was more risk tolerant. In order to do this, Panel B of Table 11 repeats the results of Panel A, but removing the cases where the husband and wife have the same level of risk tolerance and recalculating the percentages. Panel $C$ then calculates the numbers and percentages in each of the four cells that would be expected if the winning partner was independent of who was more risk tolerant (i.e., assuming that the rows and columns are independent of one another). Comparing Panels $B$ and $C$ is highly instructive, and shows that the starkest contrast between actual and expected occurs when the wife is more risk tolerant than her husband; here we would expect him to win about half the time but in reality he wins nearly $70 \%$ of the time. This percentage difference is larger than the difference between the expected and actual results for when the wife is less risk tolerance and wins.

\footnotetext{
${ }^{39}$ Unless, of course, the risk scores of the couple are an even number of digits apart and the advisor selects a product with a risk score exactly in the middle (e.g. the husband and wife have scores of 8 and 6 respectively and the finally chosen product has a risk level of 7).

${ }^{40}$ It would of course also be interesting to examine the financial decisions of same-sex married couples, but the number in our database is very small and therefore we focus on the sub-sample of marriages between men and women.
} 
This demonstrates a clear asymmetry between the likelihood that men and women will win, with risk tolerant women being the greatest losers. While Panel A of the table focused on counts of the numbers of clients with each outcome, Panel D looks at the absolute adjustments that husbands and wives must make to their own ATR in achieving the consensus. Again, this shows an asymmetry: the absolute adjustment made by the woman when the man wins is on average larger than the adjustment made by the man when the woman wins.

[Insert Table 11 about here]

Can we predict which partner is more likely to win (aside from it more often than not being the one who is the least risk tolerant)? There is much related literature upon which to make predictions about the probable outcomes in this regard. Elder and Rudolph (2003) find (based on survey evidence rather than actual financial decisions) that the 'winner' among couples is most likely to be the one who earns more, is more financially knowledgeable and better educated, and that could be the husband or the wife. Couples tend to invest a higher proportion of their wealth in equities when the husband has more decision-making power in the choice (Friedberg and Webb, 2006) and when the husband is relatively more financially knowledgeable (Yilmazer et al., 2010). However, the above studies take place in a survey context rather than reflecting the outcomes of real decisions, and there could therefore be disagreements within a couple over several of the key variables (e.g., who is more knowledgeable or who has more power in the decision, Lyons et al., 2008). By contrast, our measurement is in the context of a real choice scenario and our analysis of who effectively controls the purse strings is based on the actual outcome rather than a matter of opinion.

Some research has suggested that household finance is more often than not male-dominated, and that the husband is more likely to both select insurance products and to pay the premiums (e.g., Skinner and Dubinsky, 1984). Age is likely to be a key factor in affecting the relative balance of power as, according to social role theory, women's societal positions changed most rapidly from the 1960 s onwards, reflecting increasing equality and their greater presence in senior roles in the workforce (Twenge, 2001) and implying a greater need than previously for them to make pension decisions (Gilliam et al., 2010). Thus it is expectable that younger couples will offer a greater role to the woman's preferences in making joint decisions.

Through a series of interviews with couples making financial decisions, Wood et al. (2012) find that within couples, one partner usually takes responsibility for instigating financial decisions even when that person is not financially more competent simply because of a lack of willingness of the other partner (more often the man) to do so. That the 'alpha partner' in financial decision-making is more likely to be a woman perhaps runs counter to intuition (as expressed in Bernasek and Bajtelsmit, 2002, for example). This follows on from very early research showing that differences in educational levels do not affect the likelihood that one partner will take responsibility for financial decisions rather than the other (Ferber and Lee, 1974). 
In order to investigate these issues, Panel A of Table 12 begins by summarising the outcomes when married couples comprising a man and a woman visit the advisor together compared to the situation where they are married but visit the advisor alone. Around 62,000 married couples visit an advisor together, while around 50,000 married women and 107,000 married men visit alone. Considering first the calculated ATR (directly from the questionnaire), the risk scores for married men and women are both lower when they visit the advisor together ('joint plan') than when they visit alone ('single plan'); this difference is significant at the $1 \%$ level for both genders but the effect of attending with a partner is five times greater on men than women. When we repeat the analysis for the selected risk profile, we find that those of women who attend with a partner are actually slightly higher than those who do not, while those of men who attend with a partner are significantly lower.

\section{[Insert Table 12 about here]}

Panel B of Table 12 presents a different way of displaying the information from Panel A, and shows the average differences between the calculated and selected ATR scores for the sub-sample of married men and women - both single and joint plans. Focusing on the actual adjustment (left-hand side) first, it is clear that the effect of the advisory conversation following completion of the ATR questionnaire is to reduce the level of risk taken in all cases, but to a greater extent for men, especially when they attend with their wives. The absolute adjustments in the ATR (right-hand panel) are greatest for clients as part of a joint plan, presumably as a result of the requirement to reconcile sometimes opposing preferences within the couple.

Finally, Panel C of Table 12 highlights a further interesting feature of the data, which is an increase in the percentage of married couples who select single plans rather than a joint one, tying in with societal changes where women desire financial independence and increasingly make their own financial decisions and pension savings separate from their husbands (see, for example, Barr and Diamond, 2008). From the database, around a third of couples (approximately 5,000) had joint plans in 2011, but within just five years this had fallen to a quarter (approximately 15,000 of a fast growing total number of completed questionnaires).

To better determine the factors which impact variations in the probability of a winner partner, we create a score variable that we term Winning Wife which takes values $-1,0$ and 1 according to whether the absolute ATR adjustment of the wife is greater (winning husband), equal (no winner), or smaller (winning wife) than the absolute ATR adjustment of her spouse. We regress Winning Wife on the same independent variables as for the core results presented in Section 3.1, but this time the variables are computed as simple averages between the partners for each couple. The possible effect of the comparison between the risk tolerance of each spouse is controlled for by two dummy variables, which we term Riskier Wife and Riskier Husband. Riskier Wife is a binary variable equal to 1 when the Calculated ATR of the wife is greater than the Calculated ATR of her spouse. Riskier Husband is a binary variable equal to 1 when the Calculated ATR of the husband is 
greater than the Calculated ATR of his spouse. We might expect that the age difference between a wife and husband might play a role in determining the likelihood of one winning partner rather than the other. Thus we also include in the model specification the variable Age Spread (F-M), which is the difference between the age of the wife and the husband. In the following regressions, other variables such as Age, Capacity etc., are averaged across the couple.

Table 13, column (1) shows that the older and more financially capable of bearing losses the married couple is, the more likely is the wife to win. Columns (2), (3) and (6) present regression results with the inclusion of the dummies Riskier Wife and Riskier Husband, which are both statistically and economically significant. A more risk tolerant wife has a lower probability of winning ${ }^{41}$ by roughly $16.653 \%$ (column (3)). When the husband's Calculated ATR is greater than his wife's, the probability of a winning wife increases by $5.904 \%$ (column (3)). Perhaps surprisingly, the age difference between the female and male partners does not help much in explaining the presence of a winner when married couples interact with their advisor. ${ }^{42}$

\section{[Insert Tables 13, 14 and 15 about here]}

In Table 14, we control for the employment of the couples. Additionally, we analyse whether the wife having a more prestigious employment status with respect to her spouse helps to make her the more likely to win. We create two variables named Employment Rank and Employment Rank Spread (F-M). Employment Rank is the simple average of the employment ranks of the spouses. The individual employment rank is computed as a score variable which takes value 2 when the spouse works as "Director or Partner", 0 when the spouse is "Non-Working", and 1 otherwise. ${ }^{43}$ Employment Rank Spread (F-M) is the difference between the employment rank of the wife and the employment rank of her husband. We include also Employment Rank Spread $(\mathrm{F}-\mathrm{M})^{2}$ to control possible non-linear effects (e.g. one of the couple is a "Director or Partner" and his/her spouse is a "Non-Worker").

In columns (3), (4) and (5), the coefficient of the average employment rank of the couple negatively relates to the probability of a winning wife. We have shown in Section 3 that a more prestigious job is associated with a higher Calculated ATR. For high levels of risk tolerance, since advisors make greater downward adjustments to women's ATRs than to men's, the probability of the wife being the winner and closer to the final selected ATR is smaller than the corresponding probability of the husband being the winner. Also, the higher the employment rank spread (i.e. the more relatively prestigious is the wife's job compared to that of

\footnotetext{
${ }^{41}$ For this model specification, we report the marginal probabilities of the scenario of the wife being the "winner" (Winning Wife = 1).

${ }^{42}$ In unreported regression results, we find that non-linear terms of the age-related variables are not statistically significant.

${ }^{43}$ We choose this ranking based on the commonly perceived level of prestige of the jobs and it corresponds to a less granular version of the standard Registrar General's Classification of social class in the UK with professionals rated at the top, and other workers in a lower ranking - see, for example:

https://www.ons.gov.uk/methodology/classificationsandstandards/otherclassifications/thenationalstatisticssocioeconomicclassific ationnssecrebasedonsoc2010
} 
her husband), the more likely is the wife to win, by roughly $3.498 \%$ (column (5)). When the difference in the prestige of the partners' jobs is even higher, the probability further increases. Overall, we interpret this result as a confirmation of the social role theory. Since the social status of the employment category of the couple might influence the decision making process when selecting the final ATR.

Finally, we investigate the impact of investment experience on the determination of the winner partner. Investment Experience is the average investment experience of the couple. The investment experience for each spouse is the investor's level of experience in investing and is measured as described in Section 3. Investment Experience Spread (F-M) is the difference between the investment experience of the wife and that of her husband.

In Table 15, columns (3), (4) and (5), the coefficient of the average couple's investment experience positively relates to the probability of the wife winning the "advisory battle" (1.665\% more probable in column (5)). When the wife has a greater investment experience than her husband, her probability of winning also increases (columns (4) and (5)). After controlling for the variables Riskier Wife and Riskier Husband, a positive difference between the investment experience between the wife and her husband leads the scenario of winning wife to be more probable by $2.583 \%$ (column (5)).

\section{Conclusions and Reflection}

This paper has conducted an extensive investigation of the financial risk tolerance of men compared with women, and of the factors affecting the differences between the two. Using a database that records the outcomes from more than half a million interactions between financial advisors and their clients in the UK and associated demographic data, we are first able to confirm the results of previous studies that women are indeed significantly more risk averse than men in the investment domain. Interestingly, however, we are also able to show that the disparity is declining over time and if this trend continues, it is likely to evaporate entirely over the next two decades. When we allow for the differing ages of male and female clients visiting their financial advisors, their marital status, and for differences in employment patterns and levels of wealth, the gender effect on risk tolerance is slightly diminished but still remains. The most important explanatory factor for risk tolerance that we observe is the level of investment experience of the client, which on average is higher for men than for women. This result is consistent with the substantial evidence in existence that women on average have lower levels of financial education (Almenberg and Dreber, 2015; Dwyer et al., 2000). This factor is able to explain around $36 \%$ of the raw difference in risk tolerance score between men and women, whereas the comparable figures for the explanatory powers of employment and of marital status are respectively $7 \%$ and $<1 \%$. Our results here add to the weight of psychology literature that exposure to risk leads to a diminished fear of it in the future (e.g., Slovic et al., 2000). 
Since the database that we employ records both the clients' individual risk tolerances following the completion of a psychometric (ATR) questionnaire and the corresponding risk level of the investment proposition actually selected at the end of the process, we are able to examine the differing impact of the wider conversation between advisor and client on the riskiness of the finally selected portfolios for men and women. We observe that advisors make greater adjustments to women's choices than men's, although there is a considerable 'regression to the mean' effect where those with low specific risk tolerance are pushed up and those with high tolerance pushed down. Our findings indicate that a more nuanced view of the impact of gender on the interaction between advisors and their clients is required than suggested, for example, by Wang (1994), whose research would suggest that female clients are likely to be offered even lower risk products than their risk tolerance would indicate. We would argue that this is only the case when women have higher than average risk tolerances and in other specific contexts but not in general.

Finally, we conduct an investigation of the factors affecting the joint investment outcome when a husband and wife have conflicting individual risk preferences. We find that when one partner has a higher risk tolerance than his/her spouse, the final risk level selected after the meeting with the advisor is closer to that of the less risk averse partner. In particular, when the wife is more risk tolerant, she is far more likely to have to compromise than when her husband is more risk tolerant; when women lose, their adjustment is greater than that of men when the latter lose; when women win, their adjustment is again greater than that of men when the latter win, albeit these effects are of small magnitude.

A first potential explanation of this result is that it possibly indicates a gender bias in the advisor decision making process when meeting married couples. This effect is mitigated when the wife's job is more prestigious/senior than that of her husband and in cases where she is more experienced and knowledgeable about investing than her partner. In that sense, it is the partner with the greater investment experience who 'wears the trousers'. A second explanation is that a benevolent financial advisor is implicitly attempting to counteract perceived gender biases in investment behaviour. If the differential treatment of male and female clients reflects this and results in improved outcomes for both genders, it would be laudable - for example, if women are excessively timid in their risky investment decisions, even when investing for the very long term (such as in a pension scheme). However, the fact that women's personal risk appetites are subject to greater revisions when selecting the final investment product than men's not only when women have lower than average risk tolerances but also when they are higher is difficult to reconcile with the latter line of reasoning.

Our results have potentially important policy implications. The lower risk tolerance of women, leading to their assets being placed in low risk-low return portfolios, would be expected to lead to a reduced tendency for women to accumulate wealth when they are investing over the longer term (Jianakoplos and Bernasek, 
1998). ${ }^{44}$ There is already evidence that women accumulate significantly lower pension wealth than men, even after allowing for income, education levels and other variables (Gustman et al., 1997; Schmidt and Sevak, 2006), and this combined with their greater longevity means they are more likely to end their days in poverty (Bernasek and Shwiff, 2001). We suggest that greater financial education, which could for example begin in secondary schools, and emphasising the importance of involving both partners in household investment decision-making, would enhance financial knowledge and encourage those for whom it is appropriate to take risks with their money to do so. As our results in Table 7 show, however, a given amount of additional investment experience will increase men's risk tolerance by more than women's and thus by the same argument, greater financial education could actually exacerbate existing gender imbalances in risk aversion.

An additional suggestion is that the gender gap in investment risk taking is likely to further close with the increasing growth of the 'robo-advice' sector, where support for financial decision-making comes via an internet-based computer algorithm rather than face-to-face. Recent research indicates that women feel more free to 'be themselves' rather than conforming to a gender stereotype on-line than in a social situation (Oberst et al., 2016).

When married couples visit a financial advisor together, in many instances their risk appetites appear to coincide. But when they do not, our results suggest that women need to be more forceful in such meetings to ensure that their voices are heard and that joint financial products match their risk preferences to the same degree as those of their husbands. Advisors need to be cognisant of this potential outcome, to always conduct the session in a manner as to ensure that both parties have an equal chance to affect the final investment product selection, and to counteract socially induced forms of behaviour where women are more passive in negotiations.

We are not suggesting that advisors treat female clients less favourably than male clients, but we do uncover evidence that they treat them differently in some cases, and the reasons for this and the manner in which it occurs are both worthy of further investigation. Our findings, which are purely based on quantitative analysis of a large secondary dataset, could be underpinned and enriched by a qualitative investigation.

The fact that women have lower levels of investment experience and that this is a significant predictor of risk tolerance is suggestive of the importance of socialisation in determining this outcome. However, our measure of investment experience is self-assessed by the client and there could be systematic differences in the extents to which men and women to report this accurately using the same calibration. For example, in other domains it has been reported that men are more likely to exaggerate the strength of their knowledge, potentially feeding a false sense of confidence. If actual and reported levels of investment experience do differ in this way between men and women, it would instead indicate a possible role for nature in determining

\footnotetext{
${ }^{44}$ Interestingly, this has also been argued to have manifested itself in a reduced tendency to select risky careers in finance (Sapienza et al., 2009), although this is not the focus of the present study.
} 
gender differences in risk tolerance if it is, for example, testosterone-driven (Apicella et al., 2008) rather than arising from any attempt to follow societal norms. We cannot definitively contribute to the nature versus nurture debate given our exclusive use of anonymised secondary data, despite is numerous other advantages as outlined above. The need to shed light on these issues is suggestive of an exciting potential future research agenda where, for example, investigators could attend advisory sessions as non-participant observers to see at first hand the interactions between advisors and their clients and to examine whether there exist different dynamics when the latter are men versus women, and also whether it makes a difference whether both the advisor and the client are men compared to the situation where the advisor is a woman. 


\section{References}

Addoum, J. M. (2017) Household portfolio choice and retirement Review of Economics and Statistics 99(5), 870-883.

Addoum, J. M., Kung, H. and Morales, G. (2016) Limited marital commitment and household portfolios Working paper, Cornell University.

Agnew, J.R., Anderson, L.R., Gerlach, J.R. and Szykman, L.R. (2008) Who chooses annuities? An experimental investigation of the role of gender, framing and defaults American Economic Review Papers and Proceedings 98(2), 418-422.

Akerlof, G.A. and Kranton, R.E. (2000) Economics and identity Quarterly Journal of Economics 115(3), 715753.

Almenberg, J., and Dreber, A. (2015) Gender, stock market participation and financial literacy Economics Letters, 137, 140-142.

Anbar, A. and Eker, M. (2010) An empirical investigation for determining the relation between personal financial risk tolerance and demographic characteristics EGE Academic Review 10(2), 503-523.

Apicella, C.L., Dreber, A., Campbell, B., Gray, P.B., Hoffman, M. and Little, A.C. (2008) Testosterone and financial risk preferences Evolution and Human Behavior 29(6), 384-390.

Bajtelsmit, V.L. and Bernasek, A. (1996) Why do women invest differently than men? Financial Counseling and Planning 7, 1-10.

Bannier, C. E., and Neubert, M. (2016) Gender differences in financial risk taking: The role of financial literacy and risk tolerance Economics Letters, 145, 130-135.

Barasinka, N. and Schäfer, D. (2013) Is the willingness to take financial risks a sex-linked trait? Evidence from national surveys of household finance DIW Berlin Discussion Papers 1278.

Barber, B. M., and Odean, T. (2001) Boys will be boys: Gender, overconfidence, and common stock investment Quarterly Journal of Economics, 116(1), 261-292.

Barr, N. and Diamond, P. (2008) Reforming Pensions: Principles and Policy Choices Oxford University Press, Oxford.

Barke, R.P., Jenkins-Smith, H. and Slovic, P. (1997) Risk perceptions of men and women scientists Social Science Quarterly 78, 167-176.

Beckmann, D., Lütje, T., and Rebeggiani, L. (2011) Italian asset managers' behavior: Evidence on overconfidence, risk taking and gender Journal of Modern Accounting and Auditing, 7(12), 1368. 
Bernasek, A. and Batjelsmit, V.L. (2002) Predictors of women's involvement in household financial decisionmaking Financial Counseling and Planning 13(2), 39-47.

Bernasek, A. and Schwiff, S. (2001) Gender, risk and retirement Journal of Economic Issues 35(2), 345-356.

Beyer, S. and Bowden, E.M. (1997) Gender differences in self-perception: convergent evidence from three measures of accuracy and bias Personality and Social Psychology Bulletin 23, 157-172.

Bommier, A. and Rochet, J.C. (2006) Risk aversion and planning horizons Journal of the European Economic Association 4(4), 708-734.

Booth, A. L., and Nolen, P. (2012) Gender differences in risk behaviour: Does nurture matter? Economic Journal, 122(558), F56-F78.

Borghans, L., Heckman, J. J., Golsteyn, B. H., and Meijers, H. (2009) Gender differences in risk aversion and ambiguity aversion Journal of the European Economic Association, 7(2-3), 649-658.

Brooks, C., Sangiorgi, I., Hillenbrand, C. and Money, K. (2018) Why are older investors less willing to take financial risks? International Review of Financial Analysis, 56, 52-72.

Browne, M.J., Jaeger, V. and Steinorth, P. (2015) Impact of economic conditions on individual risk attitude Munich Risk and Insurance Center Working Paper 29.

Buss, D. (1999) Evolutionary Psychology Allyn and Bacon: Boston.

Byrnes, J.P., Miller, D.C. and Schaefer, W.D. (1999) Gender differences in risk taking: a meta-analysis Psychological Bulletin 125, 367-383.

Charness, G., and Gneezy, U. (2012) Strong evidence for gender differences in risk taking. Journal of Economic Behavior \& Organization, 83(1), 50-58.

Chow, K.V. and Riley, W. (1992) Asset allocation and individual risk aversion Financial Analysts Journal 48, 32-37.

Chung, D., Christopoulos, G. I., King-Casas, B., Ball, S. B., and Chiu, P. H. (2015) Social signals of safety and risk confer utility and have asymmetric effects on observers' choices Nature Neuroscience, 18(6), 912-916.

Craske, M.G. (2003) The Origins of Phobias and Disorders: Why More Women than Men Elsevier, Oxford, UK. Cronqvist, H., Previtero, A., Siegel, S., and White, R. E. (2016) The fetal origins hypothesis in finance: Prenatal environment, the gender gap, and investor behavior. Review of Financial Studies, 29(3), 739-786.

Croson, R. and Gneezy, U. (2009) Gender differences in preferences Journal of Economic Literature 47(2), 448-474. 
Dohmen, T., Falk, A., Huffman, D., Sunde, U., Schupp, J., and Wagner, G. G. (2011) Individual risk attitudes: Measurement, determinants, and behavioral consequences Journal of the European Economic Association $9(3), 522-550$.

Fehr-Duda, H., De Gennaro, M., and Schubert, R. (2006) Gender, financial risk, and probability weights Theory and Decision, 60(2), 283-313.

Dwyer, P.D., Gilkenson, J.H. and List, J.A. (2002) Gender differences in revealed risk taking: evidence from mutual fund investors Economic Letters 76(2), 151-158.

Eckel, C. C., \& Grossman, P. J. (2008) Men, women and risk aversion: Experimental evidence Handbook of Experimental Economics Results 1, 1061-1073.

Elder, H.W. and Rudolph, P.M. (2003) Who makes the final decisions in the households of older Americans? Financial Services Review 12(4), 293-308.

Embrey, L.L. and Fox, J.J. (1997) Gender differences in the investment decision-making process Journal of Financial Counseling and Planning 8(2), 33-39.

Felton, J., Gibson, B., and Sanbonmatsu, D. M. (2003) Preference for risk in investing as a function of trait optimism and gender Journal of Behavioral Finance, 4(1), 33-40.

Ferber, R. and Lee, L.C. (1974) Husband-wife influences in family purchasing behavior Journal of Consumer Research 1, 43-50.

Finucane, M.L., Slovic, P., Mertz, C.K., Flynn, J. and Satterfield, T.A. (2000) Gender, race, and perceived risk: the 'white male' effect Health, Risk and Society 2(2), 159-172.

Flynn, J., Slovic, P. and Mertz, C.K. (1994) Gender, race and perception of environmental health risks Risk Analysis 14(6), 1101-1108.

Forman, S., Money, A., \& Page, M. J. (1998) How reliable is reliable? A note on the estimation of Cronbach alpha. In Proceedings of the International Management Conference, Cape Town, South Africa, May 1998 (pp. 1-26).

Friedberg, L. and Webb, A. (2006) Determinants and consequences of bargaining power in households NBER Working Paper No. 12367.

Fujita, F., Diener, E. and Sandvik, E. (1991) Gender differences in negative affect and well-being: the case for emotional intensity Journal of Personality and Social Psychology 61(3), 427-434.

Gilliam, J.E., Chatterjee, S. and Zhu, D. (2010) Determinants of risk tolerance in the baby boomer cohort Journal of Business and Economics Research 8(5), 79-87. 
Gilliam, J.E., Dass, M., Durband, D.B. and Hampton, V. (2010) The role of assertiveness in portfolio risk and financial risk tolerance among married couples Journal of Financial Counseling and Planning 21(1), 53-67.

Gilligan, C. (1982) In a Different Voice: Psychological Theory and Women's Development Harvard University Press, Cambridge.

Gneezy, U., Leonard, K.L. and List, J.A. (2009) Gender differences in competition: evidence from a matrilineal and patriarchal society Econometrica 77(5), 1637-1664.

Grable, J. and Lytton, R.H. (1999) Financial risk tolerance revisited: the development of a risk assessment instrument Financial Services Review 8(3), 163-181.

Grossman, M. and Wood, W. (1993) Sex differences in intensity of emotional experience: a social role interpretation Journal of Personality and Social Psychology 65(5), 1010-1022.

Guo, G., Cai, R., Guo, R., Wang, H. and Harris, K.M. (2010) The dopamine transporter gene, a spectrum of most common risky behaviors and the legal status of the behaviors PLoS One 5(2), e9352.

Gustman, A.L., Mitchell, O.S., Samwick, A.A. and Steinmeier, T.L. (1997) Pension and social security wealth in the health and retirement study NBER Working Paper 5912.

Halko, M. L., Kaustia, M. and Alanko, E. (2012) The gender effect in risky asset holdings Journal of Economic Behavior \& Organization 83(1), 66-81.

Hallahan, T.A., Faff, R.W., and McKenzie, M.D. (2004) An empirical investigation of personal financial risk tolerance Financial Services Review 13, 57-78.

Hanna, S.D. and Lindamood, S. (2005) Risk tolerance of married couples Conference Paper, Academy of Financial Services Meeting.

Hardies, K., Breesch, D. and Branson, J. (2012) Gender differences in overconfidence and risk taking: do selfselection and socialization matter? Economics Letters 18(3), 442-444.

Harris, C.R., Jenkins, M. and Glaser, D. (2006) Gender differences in risk assessment: why do women take fewer risks than men? Judgment and Decision Making 1(1), 48-63.

Jacobsen, B., Lee, J. B., Marquering, W., and Zhang, C. Y. (2014) Gender differences in optimism and asset allocation Journal of Economic Behavior \& Organization, 107, 630-651.

Jianakoplos, N.A., Bajtelsmit, V.L. and Bernasek, A. (2003) How marriage matters to pension investment decisions Journal of Financial Services Professionals 57(2), 48-57.

Jianakoplos, N. and Bernasek, A. (1998) Are women more risk averse? Economic Inquiry 36, 620-630. 
Jianakoplos, N.A. and Bernasek, A. (2006) Financial risk taking by age and birth cohort Southern Economic Journal 72(4), 981-1001.

Kahan, D.M., Braman, D., Gastil, J., Slovic, P. and Mertz, C.K. (2007) Culture and identity-protective cognition: Explaining the white male effect in Risk Perception Journal of Empirical Legal Studies 4(3), 465-505.

Ke, D. (2017) Who Wears the Pants? Gender Identity Norms and Intra-Household Financial Decision Making. Working Paper, Darla Moore School of Business, University of South Carolina.

Konecni, V.J., Ebbesen, E.B. and Konecni, D.K. (1976) Decision processes and risk-taking in traffic: driver response to the onset of yellow light Journal of Applied Psychology 61, 359-367.

Lerner, J.S., Gonzalez, R.M., Small, D.A. and Fischhoff, B. (2003) Effects of fear and anger on perceived risks of terrorism: a national field experiment Psychological Science 14(2), 144-150.

Loewenstein, G.F., Weber, E.U., Hsee, C.K., and Welch, N. (2001) Risk as Feelings Psychological Bulletin 127(2), 267-286.

Lusardi, A. and Mitchell, O.S. (2008) Planning and financial literacy: how do women fare? American Economic Review Papers and Proceedings 98(2), 413-417.

Long, J. S., and Freese, J. (2006). Regression models for categorical dependent variables using Stata. Stata Press.

Lyons, A., Neelakantan, U., and Scherpf, E. (2008) Gender and marital differences in wealth and investment decisions Journal of Personal Finance, 6(4), 57.

McCann, S.J.H., Stewin, L.L. and Short, R.H. (1991) Sex differences, social desirability, masculinity and the tendency to worry Journal of Genetic Psychology 152(3), 295-301.

Oberst, U., Renau, V., Chamarro, A., and Carbonell, X. (2016). Gender stereotypes in Facebook profiles: Are women more female online? Computers in Human Behavior 60, 559-564.

Olsen, R.A. and Cox, C.M. (2001) The influence of gender on the perception and response to investment risk: the case of professional investors Journal of Psychology and Financial Markets 2, 29-36.

Ricciardi, V. (2008) The financial psychology of worry and women Working Paper, Kentucky State University. Sapienza, P., Zingales, L. and Maestripieri, D. (2009) Gender differences in financial risk aversion and career choices are affected by testosterone PNAS 106(36), 15268-15273.

Schmidt, L. and Sevak, P. (2006) Gender, marriage, and asset accumulation in the United States Feminist Economics 12(1-2), 139-166. 
Schubert, R., Brown, M., Gysler, M. and Brachinger, H.W. (1999) Financial decision-making: are women really more risk averse? AEA Papers and Proceedings 89(2), 381-385.

Stenstrom, E., Saad, G., Nepomuceno, M.V. and Mendenhall, Z. (2011) Testosterone and domain-specific risk: digit ratios ( $2 \mathrm{~d}: 4 \mathrm{~d}$ and rel2) as predictors of recreational, financial and social risk-taking behaviors Personality and Individual Differences 51(4), 412-416.

Siergrist, M., Cvetkovich, G. and Gutscher, H. (2002) Risk preference predictions and gender stereotypes Organizational Behavior and Human Decision Processes 87(1), 91-102.

Skinner, S.J. and Dubinsky, A.J. (1984) Purchase insurance: predictors of family decision-making responsibility Journal of Risk and Insurance 51(3), 513-523.

Slade, T., Chapman, C., Swift, W., Keyes, K., Tonks, Z. and Teesson, M. (2016) Birth cohort trends in the global epidemiology of alcohol use and alcohol-related harms in men and women: systematic review and metaregression BMJ Open 6, 1-12.

Slovic, P. (1966) Risk taking in children: age and sex differences Child Development 37, 169-176.

Slovic, P., Fischhoff, B. and Lichtenstein, S. (2000) Facts and fears: understanding perceived risk in Slovic, P. (ed.) The Perception of Risk Earthscan, Sterling, Virginia.

Slovic, P., Malmfors, T., Mertz, C.K., Neil, N., and Purchase, I.F.H. (1997) Evaluating chemical risks: results of a survey of the British Toxicology Society Human and Experimental Toxicology 16, 289-304.

Stevenson, B. and Wolfers, J. (2007) The paradox of declining female happiness Working Paper Series 17, University of Pennsylvania.

Thompson, A.L., Molina, B.S., Pelham, W. and Gnagy, E.M. (2007) Risky driving in adolescents and young adults with childhood ADHD Journal of Paediatric Psychology 32(7), 745-759.

Thörnqvist, T., and Vardardottir, A. (2014). Bargaining over risk: The impact of decision power on household portfolios. Paper presented at the 19th Annual Meetings of the Society of Labour Economists. SOLE 2014

Twenge, J.M. (2001) Changes in women's assertiveness in response to status and roles: a cross-temporal meta-analysis 1931-1993 Journal of Personality and Social Psychology 81(1), 133-145.

Uccello, C.E. (2000) Do spouses coordinate their investment decisions in order to share risks? Working Paper 2000-09 Centre for Retirement Research, Boston College.

Van Rooij, M., Lusardi, A. and Alessie, R. (2011) Financial literacy and stock market participation Journal of Financial Economics 101, 449-472. 
Waldron, I., McCloskey, C. and Erle, I. (2005) Trends in gender differences in accident mortality: relationships to changing gender roles and other societal trends Demographic Research 13, 415-454.

Wang, P. (1994) Brokers still treat men better than women Money 23(6), 108-110.

Weber, E.U., Blais, A-R. and Betz, N. (2002) A domain-specific risk -attitude scale: measuring risk perceptions and risk behaviors Journal of Behavioral Decision Making 15, 263-290.

Williams, R. (2012) Using the margins command to estimate and interpret adjusted predictions and marginal effects. Stata Journal, 12(2), 308.

Wilson, M. and Daly, M. (1985) Competitiveness, risk taking and violence: the young male syndrome Ethology and Sociobiology 6, 59-73.

Wood, A., Downer, K., Lees, B. and Toberman, A. (2012) Household financial decision making: qualitative research with couples Research Report, Department for Work and Pensions, UK.

Yao, R. and Hanna, S.D. (2005) The effect of gender and marital status on financial risk tolerance Journal of Personal Finance 4(1), 66-85.

Yilmazer, T., and Lyons, A. C. (2010) Marriage and the allocation of assets in women's defined contribution plans Journal of Family and Economic Issues, 31(2), 121-137.

Zuckerman, M (1994) Behavioral Expressions and Biosocial Bases of Sensation Seeking Cambridge University Press, New York. 


\section{Figures and Tables}

Figure 1: Attitude to Risk (ATR) by Gender and ATR Spread between Male and Female Clients over time

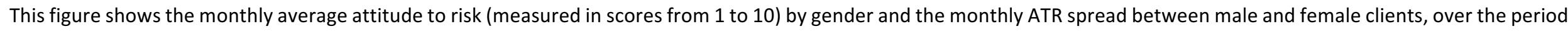
from 1 January 2011 to 31 December 2016

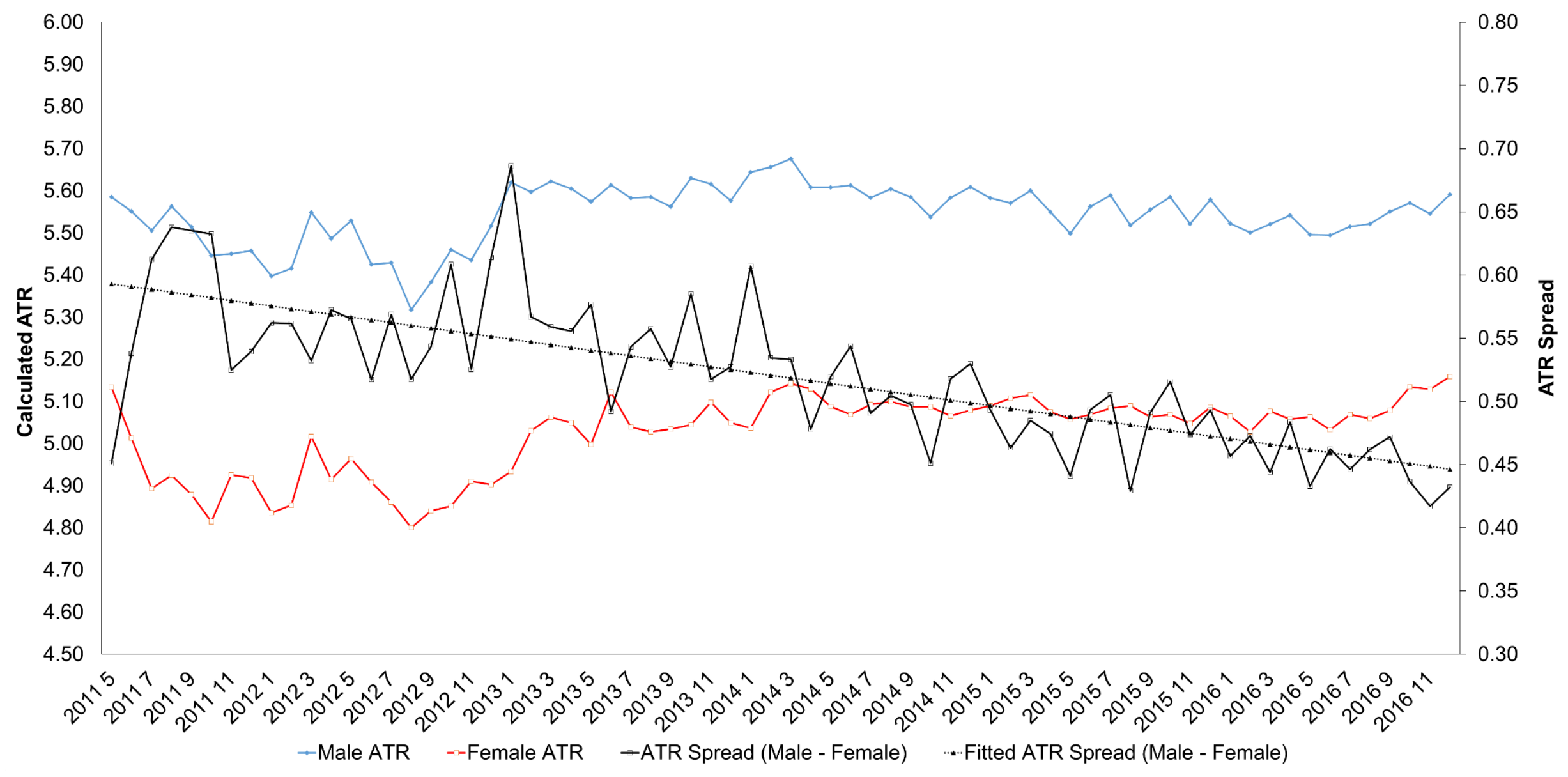




\section{Figure 2: Estimated Probability Distribution of Attitude to Risk by Gender}

This figure shows the estimated probabilities (percentage) of a client falling into a certain attitude to risk category (Calculated ATR), measured in integer scores from 1 to 10 , by gender over the period from 1 January 2011 to 31 December 2016. The estimated model is an ordered probit with robust standard errors, gender dummy, age, age ${ }^{2}$ and time fixed effects (year). Age and time fixed effects are assumed at their sample mean values. All probabilities are significant at the $1 \%$ level.

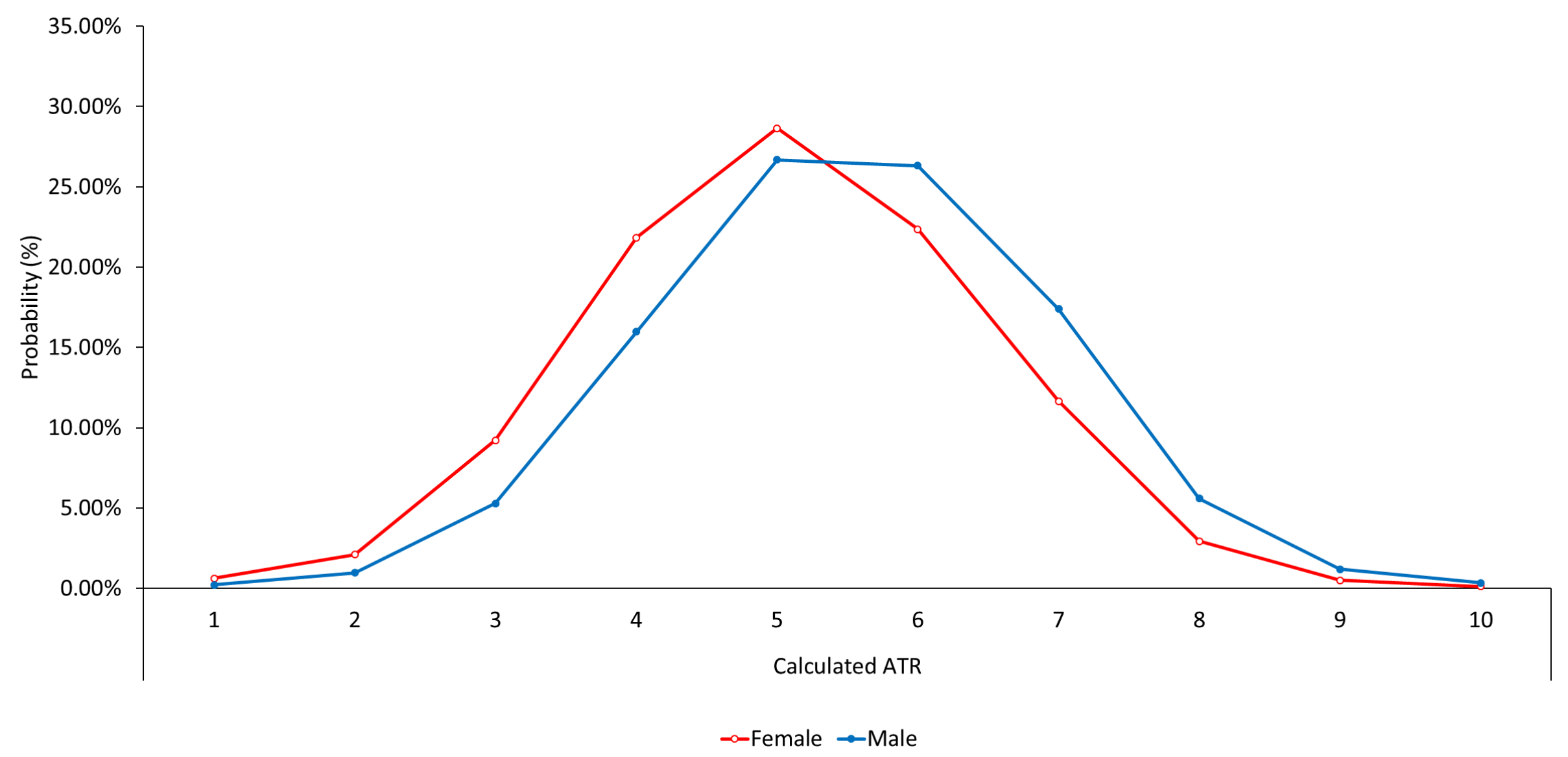




\section{Table 1: Summary statistics of attitude to risk by gender}

This table reports summary statistics of attitude to risk by gender over the sample period 1 January 2011 to 31 December 2016. Calculated ATR is the attitude to risk of the investor (integer scores from 1 to 10, where 10 indicates the highest tolerance risk level and 1 the lowest). Age (measured in years) is the investor's age. Capacity is the investor's ability to bear losses. Time is the investor's time horizon of investment. Liquidity is the investor's expected urgency to access investments. Capacity, Time and Liquidity are all measured as score variables from 0 to 2, where 0 indicates a low level and 2 a high level. Panel A presents the summary statistics of attitude to risk by gender; Panel B reports the summary statistics by both gender and 5-year age buckets; Panel C presents Spearman's correlation matrix of attitude to risk, age, capacity, time and liquidity by gender. ${ }^{*}, * *$ and $* * *$ indicate significance at the $10 \%, 5 \%$ and $1 \%$ levels respectively.

\begin{tabular}{cccc}
\hline \multicolumn{2}{c}{ Panel A: Summary Statistics for Calculated ATR } & \\
\hline Mean & All & Female & Male \\
Median & 5.344 & 5.054 & 5.554 \\
Standard Deviation & 5.000 & 5.000 & 6.000 \\
Minimum & 1.447 & 1.366 & 1.468 \\
Maximum & 1.000 & 1.000 & 1.000 \\
No. of Observations & 10.000 & 10.000 & 10.000 \\
Percentage & 533,518 & 223,701 & 309,817 \\
\hline
\end{tabular}

Panel B: Summary Statistics for Calculated ATR by Gender and Age

\begin{tabular}{|c|c|c|c|c|c|c|c|c|}
\hline \multirow{2}{*}{ Age Bucket } & \multicolumn{4}{|c|}{ Number of completed questionnaires } & \multicolumn{4}{|c|}{ Average Calculated ATR } \\
\hline & All & Female & Male & $\%$ Female & All & Female & Male & Difference \\
\hline$<30$ & 12,346 & 4,817 & 7,529 & $39.02 \%$ & 5.712 & 5.379 & 5.925 & $-0.546 * * *$ \\
\hline$[30: 34]$ & 11,245 & 4,554 & 6,691 & $40.50 \%$ & 5.850 & 5.456 & 6.118 & $-0.662 * * *$ \\
\hline [35:39] & 18,416 & 7,387 & 11,029 & $40.11 \%$ & 5.929 & 5.548 & 6.184 & $-0.636 * * *$ \\
\hline$[40: 44]$ & 34,169 & 13,450 & 20,719 & $39.36 \%$ & 5.890 & 5.510 & 6.137 & $-0.626 * * *$ \\
\hline [45:49] & 53,805 & 21,088 & 32,717 & $39.19 \%$ & 5.766 & 5.396 & 6.005 & $-0.609 * * *$ \\
\hline [50:54] & 68,010 & 27,187 & 40,823 & $39.98 \%$ & 5.585 & 5.241 & 5.814 & $-0.573 * * *$ \\
\hline [55:59] & 84,830 & 34,316 & 50,514 & $40.45 \%$ & 5.328 & 5.040 & 5.523 & $-0.483 * * *$ \\
\hline [60:64] & 84,812 & 35,812 & 49,000 & $42.23 \%$ & 5.108 & 4.869 & 5.283 & $-0.415 * * *$ \\
\hline [65:69] & 75,721 & 29,916 & 45,805 & $39.51 \%$ & 5.060 & 4.880 & 5.177 & $-0.297 * * *$ \\
\hline [70:74] & 42,186 & 19,577 & 22,609 & $46.41 \%$ & 5.050 & 4.850 & 5.224 & $-0.374 * * *$ \\
\hline [75:79] & 24,905 & 12,567 & 12,338 & $50.46 \%$ & 4.920 & 4.737 & 5.106 & $-0.369 * * *$ \\
\hline$>=80$ & 23,073 & 13,030 & 10,043 & $56.47 \%$ & 4.789 & 4.663 & 4.953 & $-0.290 * * *$ \\
\hline All ages & 533,518 & 223,701 & 309,817 & $41.93 \%$ & 5.344 & 5.054 & 5.554 & $-0.499 * * *$ \\
\hline
\end{tabular}

\begin{tabular}{|c|c|c|c|c|c|}
\hline \multicolumn{6}{|c|}{ Panel C: Spearman's Correlation } \\
\hline Gender & Var. & $\begin{array}{c}\text { Calculated } \\
\text { ATR }\end{array}$ & Age & Capacity & Time \\
\hline \multirow{4}{*}{ All } & Age & $-0.2276 * * *$ & & & \\
\hline & Capacity & $0.3954 * * *$ & $-0.0453 * * *$ & & \\
\hline & Time & $0.1922 * * *$ & $-0.3881 * * *$ & $0.1768^{* * *}$ & \\
\hline & Liquidity & $0.0916 * * *$ & -0.0002 & $0.1772 * * *$ & $0.1195^{* * *}$ \\
\hline \multirow{4}{*}{ Female } & Age & $-0.1861 * * *$ & & & \\
\hline & Capacity & $0.3765^{* * *}$ & -0.0007 & & \\
\hline & Time & $0.1715^{* * *}$ & $-0.3540 * * *$ & $0.1604 * * *$ & \\
\hline & Liquidity & $0.0863 * * *$ & $0.0182 * * *$ & $0.1815^{* * *}$ & $0.1094 * * *$ \\
\hline \multirow{4}{*}{ Male } & Age & $-0.2458 * * *$ & & & \\
\hline & Capacity & $0.4067 * * *$ & $-0.0755 * * *$ & & \\
\hline & Time & $0.1982 * * *$ & $-0.4102 * * *$ & $0.1859 * * *$ & \\
\hline & Liquidity & $0.0985 * * *$ & $-0.0144 * * *$ & $0.1747 * * *$ & $0.1268 * * *$ \\
\hline
\end{tabular}


Table 2: Attitude to Risk and Gender- Ordered Probit regressions results

This table reports the results of ordered probit regressions estimated with robust standard errors and time fixed effects (years). Period: 1 January 2011 - 31 December 2016. Other variable definitions and measurements are explained in the notes to Table 1 . Male is a binary variable which equals one if the investor's gender is male, and zero otherwise. $\mathbf{A g e}^{2}$ is measured in years / 1,000. 10 Question Questionnaire is a dummy variable which equals one if the questionnaire is the 10 question version, and zero otherwise. Z-tests are reported in parentheses. Marginal effects (in italics) are reported in percentages. *, ** and $* * *$ indicate significance at the $10 \%, 5 \%$ and $1 \%$ levels respectively.

\begin{tabular}{|c|c|c|c|c|c|c|c|c|c|}
\hline Dep. Var. Calculated ATR & (1) & (2) & (3) & (4) & (5) & (6) & (7) & (8) & (9) \\
\hline \multicolumn{10}{|l|}{ Ind. Variables: } \\
\hline \multirow[t]{3}{*}{ Male } & $0.3521 * * *$ & $0.2920 * * *$ & $0.2035^{* * *}$ & $0.3233^{* * *}$ & $0.2689 * * *$ & $0.3281 * * *$ & $0.2920 * * *$ & $0.3018^{* * *}$ & $0.1795^{* * *}$ \\
\hline & $(126.24)$ & $(116.75)$ & $(43.17)$ & (119.99) & $(44.53)$ & $(121.42)$ & (34.79) & $(117.21)$ & $(14.41)$ \\
\hline & $3.914 \%$ & $4.347 \%$ & $4.373 \%$ & $3.998 \%$ & $4.005 \%$ & $4.028 \%$ & $4.028 \%$ & $4.392 \%$ & $4.383 \%$ \\
\hline \multirow[t]{3}{*}{ Age } & & $-0.0026 * * *$ & $-0.0025 * * *$ & $-0.0101 * * *$ & $-0.0100 * * *$ & $-0.0139 * * *$ & $-0.0139 * * *$ & $-0.0012^{* *}$ & -0.0001 \\
\hline & & $(-4.29)$ & $(-4.08)$ & $(-15.41)$ & $(-15.22)$ & $(-21.04)$ & $(-20.99)$ & $(-2.00)$ & $(-0.12)$ \\
\hline & & $-0.233 \%$ & $-0.233 \%$ & $-0.160 \%$ & $-0.160 \%$ & $-0.206 \%$ & $-0.206 \%$ & $-0.171 \%$ & $-0.210 \%$ \\
\hline \multirow[t]{3}{*}{ Age $^{2}$} & & $-0.1126 * * *$ & $-0.1131 * * *$ & $-0.0242 * * *$ & $-0.0254 * * *$ & $-0.0245 * * *$ & $-0.0247 * * *$ & $-0.0905 * * *$ & $-0.1201 * * *$ \\
\hline & & $(-21.48)$ & $(-21.59)$ & $(-4.30)$ & $(-4.51)$ & $(-4.31)$ & $(-4.34)$ & $(-16.90)$ & $(-23.06)$ \\
\hline & & - & - & - & - & - & - & - & - \\
\hline \multirow[t]{3}{*}{10 Question Questionnaire } & & $-0.1875 * * *$ & $-0.1873 * * *$ & $-0.2339 * * *$ & $-0.2339 * * *$ & $-0.2295^{* * *}$ & $-0.2294 * * *$ & $-0.2063 * * *$ & $-0.1882 * * *$ \\
\hline & & $(-75.13)$ & $(-75.11)$ & $(-86.68)$ & $(-86.68)$ & $(-84.87)$ & $(-84.85)$ & $(-80.08)$ & $(-75.67)$ \\
\hline & & $-2.791 \%$ & $-2.796 \%$ & $-2.892 \%$ & $-2.894 \%$ & $-2.818 \%$ & $-2.817 \%$ & $-3.002 \%$ & $-2.825 \%$ \\
\hline \multirow[t]{3}{*}{ Capacity } & & $0.7275^{* * *}$ & $0.6666 * * *$ & & & & & & $0.6511 * * *$ \\
\hline & & $(277.84)$ & (177.17) & & & & & & $(104.45)$ \\
\hline & & $10.830 \%$ & $10.873 \%$ & & & & & $5.209 \%$ & $10.465 \%$ \\
\hline \multirow[t]{3}{*}{ Capacity * Male } & & & $0.1062^{* * *}$ & & & & & & $0.0892 * * *$ \\
\hline & & & $(21.45)$ & & & & & & $(10.92)$ \\
\hline & & & - & & & & & & - \\
\hline \multirow[t]{3}{*}{ Time } & & & & $0.2239 * * *$ & $0.1961 * * *$ & & & & $0.0937 * * *$ \\
\hline & & & & $(93.83)$ & (54.93) & & & & (20.69) \\
\hline & & & & $2.768 \%$ & $2.752 \%$ & & & $3.622 \%$ & $1.493 \%$ \\
\hline \multirow[t]{3}{*}{ Time $*$ Male } & & & & & $0.0453^{* * *}$ & & & & $0.0167 * * *$ \\
\hline & & & & & (10.04) & & & & $(2.84)$ \\
\hline & & & & & - & & & & - \\
\hline \multirow[t]{3}{*}{ Liquidity } & & & & & & $0.1917^{* * *}$ & $0.1788^{* * *}$ & & $0.0538 * * *$ \\
\hline & & & & & & $(79.85)$ & $(49.80)$ & & $(13.88)$ \\
\hline & & & & & & $2.354 \%$ & $2.352 \%$ & $2.671 \%$ & $0.816 \%$ \\
\hline \multirow[t]{3}{*}{ Liquidity*Male } & & & & & & & $0.022 * * *$ & & 0.006 \\
\hline & & & & & & & $(4.57)$ & & $(1.16)$ \\
\hline & & & & & & & - & & - \\
\hline \multirow[t]{3}{*}{ Capacity*Time*Liquidity } & & & & & & & & $0.1801 * * *$ & $-0.0054^{* *}$ \\
\hline & & & & & & & & $(221.77)$ & $(-2.09)$ \\
\hline & & & & & & & & - & - \\
\hline \multirow[t]{3}{*}{ Capacity*Time*Liquidity*Male } & & & & & & & & & 0.0044 \\
\hline & & & & & & & & & $(1.32)$ \\
\hline & & & & & & & & & - \\
\hline Observations & 533,518 & 533,518 & 533,518 & 533,518 & 533,518 & 533,518 & 533,518 & 533,518 & 533,518 \\
\hline Time FE (Year) & Y & Y & Y & Y & Y & $\mathrm{Y}$ & Y & Y & $\mathrm{Y}$ \\
\hline $\begin{array}{c}\Delta \text { Predicted ATR (Male - } \\
\text { Female) }\end{array}$ & 0.4988 & 0.4135 & 0.4147 & 0.4580 & 0.4603 & 0.4647 & 0.4650 & 0.4275 & 0.4135 \\
\hline Pseudo $\mathrm{R}^{2}$ & 0.00854 & 0.0736 & 0.0739 & 0.0303 & 0.0304 & 0.0289 & 0.0289 & 0.0561 & 0.0755 \\
\hline
\end{tabular}


Table 3: Summary statistics of attitude to risk by gender, employment status and marital status

This table reports summary statistics of attitude to risk by gender, employment status and marital status over the sample period 1 January 2011 to 31 December 2016. Director or Partner, Employed and Self-Employed, Self-Employed, Employed, House-Person, Semi-Retired, Non-Working and Retired are all binary variables which equal one according to the employment status of the investor, and zero otherwise. Single, Civil Partnership, Married, Divorced and Widowed are all binary variables which equal one according to the marital status of the investor, and zero otherwise. Panel A represents the summary statistics of attitude to risk by gender and employment status; Panel B reports the summary statistics of attitude to risk by gender and marital status. ${ }^{*}, * *$ and $* * *$ indicate significance at the $10 \%, 5 \%$ and $1 \%$ levels respectively.

\begin{tabular}{|c|c|c|c|c|c|c|c|c|c|c|c|c|c|c|c|c|c|}
\hline \multicolumn{18}{|c|}{ Panel A: Summary Statistics for Calculated ATR by Gender and Employment Status } \\
\hline \multirow{2}{*}{\multicolumn{2}{|c|}{ Employment Status }} & \multicolumn{8}{|c|}{ Number of completed questionnaires } & \multicolumn{5}{|c|}{ Average Calculated ATR } & \multicolumn{3}{|c|}{ Average Age } \\
\hline & & \multicolumn{2}{|r|}{ Female } & \multicolumn{2}{|c|}{ Male } & \multicolumn{2}{|c|}{$\%$ All } & \multicolumn{2}{|c|}{$\%$ Female } & \multicolumn{3}{|c|}{ Female } & Male & $\begin{array}{c}\text { Diff. } \\
\text { (Female - } \\
\text { Male) }\end{array}$ & All & Female & Male \\
\hline \multicolumn{2}{|c|}{ Director or Partner } & 2,217 & 561 & \multicolumn{2}{|c|}{1,656} & \multicolumn{2}{|c|}{$4.41 \%$} & \multicolumn{2}{|c|}{$25.30 \%$} & 6.150 & \multicolumn{2}{|c|}{5.784} & 6.274 & $-0.489 * * *$ & 51.694 & 51.114 & 51.890 \\
\hline \multicolumn{2}{|c|}{ Employed/Self Employed } & 645 & 211 & \multicolumn{2}{|c|}{434} & \multicolumn{2}{|c|}{$1.28 \%$} & \multicolumn{2}{|c|}{$32.71 \%$} & 5.924 & \multicolumn{2}{|c|}{5.588} & 6.088 & $-0.500 * * *$ & 51.816 & 50.711 & 52.353 \\
\hline \multicolumn{2}{|c|}{ Self Employed } & 5,656 & 1,613 & \multicolumn{2}{|c|}{4,043} & \multicolumn{2}{|c|}{$11.24 \%$} & \multicolumn{2}{|c|}{$28.52 \%$} & 5.809 & \multicolumn{2}{|c|}{5.541} & 5.916 & $-0.375 * * *$ & 53.861 & 52.602 & 54.363 \\
\hline \multicolumn{2}{|c|}{ Employed } & 23,293 & 9,048 & 14, & 245 & 46.3 & & 38. & $4 \%$ & 5.676 & 5.3 & 37 & 5.892 & $-0.555 * * *$ & 50.652 & 50.444 & 50.784 \\
\hline House-Pers & & 955 & 899 & & 6 & 1.9 & & 94. & $4 \%$ & 5.440 & 5.4 & 157 & 5.161 & $0.296 * * *$ & 52.333 & 52.280 & 53.179 \\
\hline Semi-Retir & & 870 & 326 & & 44 & 1.7 & & 37. & $7 \%$ & 5.424 & 5.0 & 86 & 5.627 & $-0.541 * * *$ & 65.084 & 64.558 & 65.399 \\
\hline Non-Work & & 1,017 & 447 & & 70 & 2.0 & & 43. & $5 \%$ & 5.396 & 5.2 & 39 & 5.519 & $-0.280 * * *$ & 50.072 & 48.685 & 51.160 \\
\hline Retired & & 15,647 & 8,029 & & 18 & 31.1 & & 51. & $1 \%$ & 5.050 & 4.8 & 71 & 5.239 & $-0.368 * * *$ & 69.941 & 70.117 & 69.756 \\
\hline All & & 50,300 & 21,134 & 29, & 166 & 100. & $0 \%$ & 42. & $2 \%$ & 5.506 & 5.1 & 89 & 5.736 & $-0.547 * * *$ & 57.344 & 58.362 & 56.606 \\
\hline & & & Panel B: & umr & nary & tatisti & s for & Calcu & ated AT & R by Ger & ider & and $\mathrm{N}$ & Aarital S & atus & & & \\
\hline & & Number of & complet & d q & destio & nnaire & & & & Ave & rage & Calcu & dlated $A$ & & & Average $A$ & \\
\hline Marital Status & All & Female & Mal & & $\%$ & All & & & All & Fema & & Mal & $(\mathrm{Fe}$ & $\begin{array}{l}\text { Diff. } \\
\text { male - Male) }\end{array}$ & All & Female & Male \\
\hline Single & 63,334 & 26,103 & 37,2 & & 16. & $94 \%$ & 41. & $21 \%$ & 5.449 & 5.12 & & 5.67 & & $-0.553 * * *$ & 52.053 & 53.573 & 50.988 \\
\hline Civil Partnership & 1,969 & 805 & 1,16 & & 0.5 & $3 \%$ & 40. & $38 \%$ & 5.433 & 5.23 & & 5.57 & & $-0.338 * * *$ & 53.213 & 53.314 & 53.143 \\
\hline Married & 266,611 & 107,215 & 159,3 & & 71. & $29 \%$ & 40. & $21 \%$ & 5.336 & 5.08 & & 5.50 & & $-0.423 * * *$ & 58.948 & 58.677 & 59.130 \\
\hline Divorced & 19,748 & 11,192 & 8,55 & & 5.2 & $8 \%$ & 56. & $57 \%$ & 5.277 & 5.00 & & 5.63 & & $-0.629 * * *$ & 58.207 & 58.354 & 58.014 \\
\hline Widowed & 22,298 & 16,838 & 5,46 & & 5.9 & $6 \%$ & 75. & $51 \%$ & 4.867 & 4.77 & & 5.14 & & $-0.361 * * *$ & 71.914 & 72.128 & 71.254 \\
\hline All & 373,960 & 162,153 & 211,8 & & 100 & $00 \%$ & 43. & $36 \%$ & 5.325 & 5.05 & & 5.53 & & $-0.479 * * *$ & 58.484 & 59.203 & 57.934 \\
\hline
\end{tabular}




\section{Table 4: Attitude to Risk, gender and employment - Ordered Probit regressions results}

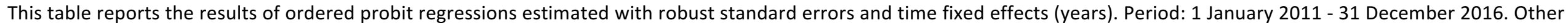

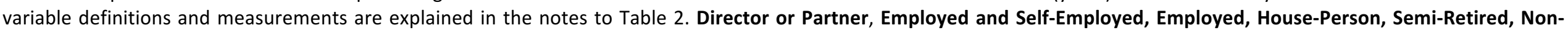

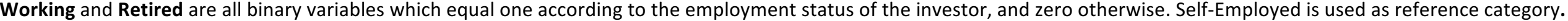

Z-tests are reported in parentheses. Marginal effects are reported in percentages. ${ }^{*}, * *$ and $* * *$ indicate significance at the $10 \%, 5 \%$ and $1 \%$ levels respectively.

\begin{tabular}{|c|c|c|c|c|c|c|c|c|c|c|c|c|c|c|c|}
\hline \multirow{2}{*}{ Dep. Var. Calculated ATR } & \multicolumn{3}{|c|}{ (1) } & \multicolumn{3}{|c|}{ (2) } & \multicolumn{3}{|c|}{ (3) } & \multicolumn{3}{|c|}{ (4) } & \multicolumn{3}{|c|}{ (5) } \\
\hline & Coeff. & z & M.E. (\%) & Coeff. & $z$ & M.E. (\%) & Coeff. & $z$ & M.E. (\%) & Coeff. & z & M.E. (\%) & Coeff. & $z$ & M.E. (\%) \\
\hline \multicolumn{16}{|l|}{ Ind. Variables: } \\
\hline Male & $0.3880 * * *$ & 42.90 & $3.389 \%$ & $0.3418^{* * *}$ & 38.65 & $3.526 \%$ & $0.2587^{* * *}$ & 17.80 & $3.543 \%$ & $0.3135^{* * *}$ & 37.42 & $3.664 \%$ & $0.2540 * * *$ & 18.13 & $3.661 \%$ \\
\hline Age & & & & $-0.026 * * *$ & -11.77 & $-0.185 \%$ & $-0.0257^{* * *}$ & -11.65 & $-0.189 \%$ & $-0.0119 * * *$ & -5.74 & $-0.149 \%$ & $-0.0117^{* * *}$ & -5.66 & $-0.153 \%$ \\
\hline Age $^{2}$ & & & & $0.0708^{* * *}$ & 3.61 & - & $0.0678^{* * *}$ & 3.46 & - & -0.0076 & -0.41 & - & -0.0096 & -0.52 & - \\
\hline 10 Question Questionnaire & & & & $-0.2522 * * *$ & -25.04 & $-2.602 \%$ & $-0.2516^{* * *}$ & -24.98 & $-2.652 \%$ & $-0.1624 * * *$ & -17.28 & $-1.899 \%$ & $-0.1620 * * *$ & -17.23 & $-1.929 \%$ \\
\hline Capacity & & & & & & & & & & $0.5500 * * *$ & 40.37 & $6.104 \%$ & $0.5500 * * *$ & 40.40 & $6.210 \%$ \\
\hline Liquidity & & & & & & & & & & $0.0494 * * *$ & 5.16 & $0.395 \%$ & $0.0493^{* * *}$ & 5.17 & $0.396 \%$ \\
\hline Capacity*Time*Liquidity & & & & & & & & & & $-0.0128 * *$ & -2.52 & - & $-0.0131 * * *$ & -2.59 & - \\
\hline Director or Partner & & & & $0.3573 * * *$ & 14.74 & $2.602 \%$ & $0.2904 * * *$ & 6.72 & $2.672 \%$ & $0.3884 * * *$ & 17.06 & $3.599 \%$ & $0.3341 * * *$ & 8.26 & $3.656 \%$ \\
\hline Employed/Self Employed & & & & $0.2516 * * *$ & 6.17 & $2.222 \%$ & $0.1565^{* *}$ & 2.23 & $2.264 \%$ & $0.2648^{* * *}$ & 6.79 & $3.002 \%$ & $0.2010 * * *$ & 2.96 & $3.042 \%$ \\
\hline Self Employed & & & & $0.1876^{* * *}$ & 10.97 & $1.824 \%$ & $0.1560 * * *$ & 5.92 & $1.920 \%$ & $0.2469 * * *$ & 15.20 & $2.870 \%$ & $0.2366 * * *$ & 9.29 & $2.971 \%$ \\
\hline Employed & & & & $0.0687^{* * *}$ & 5.02 & $0.776 \%$ & -0.0127 & -0.75 & $0.836 \%$ & $0.1522^{* * *}$ & 11.70 & $1.990 \%$ & $0.0922 * * *$ & 5.68 & $2.045 \%$ \\
\hline House-Person & & & & $0.1020 * * *$ & 3.11 & $1.109 \%$ & $0.0900 * * *$ & 2.66 & $-2.180 \%$ & $0.1359 * * *$ & 4.33 & $1.809 \%$ & $0.1351^{* * *}$ & 4.16 & $-1.957 \%$ \\
\hline Semi-Retired & & & & $0.1109 * * *$ & 3.47 & $1.192 \%$ & 0.0316 & 0.69 & $1.253 \%$ & $0.1339 * * *$ & 4.42 & $1.786 \%$ & 0.0444 & 1.01 & $1.814 \%$ \\
\hline Director or Partner * Male & & & & & & & $0.1167^{* *}$ & 2.34 & - & & & & $0.0922 * *$ & 1.98 & - \\
\hline $\begin{array}{l}\text { Employed/Self Employed * } \\
\text { Male }\end{array}$ & & & & & & & $0.1626^{*}$ & 1.91 & - & & & & 0.1101 & 1.35 & - \\
\hline Self Employed * Male & & & & & & & $0.0691 * *$ & 2.22 & - & & & & 0.0322 & 1.08 & - \\
\hline Employed * Male & & & & & & & $0.1483^{* * *}$ & 7.60 & - & & & & $0.1088^{* * *}$ & 5.85 & - \\
\hline House-Person * Male & & & & & & & $-0.4248^{* * *}$ & -3.27 & - & & & & $-0.4365 * * *$ & -3.46 & - \\
\hline Semi-Retired $*$ Male & & & & & & & $0.1443 * *$ & 2.30 & - & & & & $0.1557^{* * *}$ & 2.62 & - \\
\hline Non-Working * Male & & & & & & & -0.029 & -0.42 & - & & & & -0.026 & -0.40 & - \\
\hline Observations & 50,300 & & & 50,300 & & & 50,300 & & & 50,300 & & & 50,300 & & \\
\hline Time FE (Year) & Y & & & Y & & & Y & & & Y & & & Y & & \\
\hline $\begin{array}{l}\Delta \text { Predicted ATR (Male - } \\
\text { Female) }\end{array}$ & 0.5484 & & & 0.4832 & & & 0.4753 & & & 0.4429 & & & 0.4344 & & \\
\hline Pseudo $\mathrm{R}^{2}$ & 0.0105 & & & 0.0362 & & & 0.0366 & & & 0.0689 & & & 0.0692 & & \\
\hline
\end{tabular}




\section{Table 5: Attitude to risk, gender and marital status - Ordered Probit regressions results}

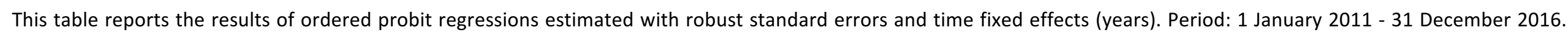

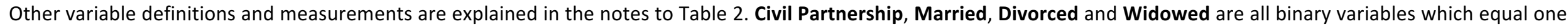

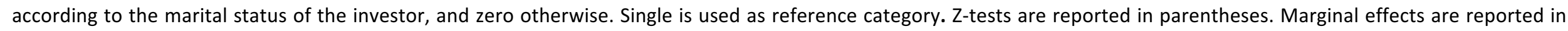
percentage. ${ }^{*}, * *$ and $* * *$ indicate significance at the $10 \%, 5 \%$ and $1 \%$ levels respectively.

\begin{tabular}{|c|c|c|c|c|c|c|c|c|c|c|c|c|c|c|c|c|c|c|}
\hline \multirow{2}{*}{ Dep. Var. Calculated ATR } & \multicolumn{3}{|c|}{ (1) } & \multicolumn{3}{|c|}{ (2) } & \multicolumn{3}{|c|}{ (3) } & \multicolumn{3}{|c|}{ (4) } & \multicolumn{3}{|c|}{ (5) } & \multicolumn{3}{|c|}{ (6) } \\
\hline & Coeff. & $z$ & M.E. $(\%)$ & Coeff. & $\mathrm{z}$ & M.E. $(\%)$ & Coeff. & z & M.E. (\%) & Coeff. & z & M.E. (\%) & Coeff. & $\mathrm{z}$ & M.E. $(\%)$ & Coeff. & $\mathrm{z}$ & M.E. (\%) \\
\hline \multicolumn{19}{|l|}{ Ind. Variables: } \\
\hline Male & $0.3411^{* * *}$ & 102.65 & $3.936 \%$ & $0.3225^{* * *}$ & 95.65 & $3.744 \%$ & $0.3214^{* * *}$ & 98.01 & $4.104 \%$ & $0.3499 * * *$ & 43.67 & $4.094 \%$ & $0.2916^{* * *}$ & 96.63 & $4.548 \%$ & $0.2821^{* * *}$ & 38.7 & $4.537 \%$ \\
\hline Age & & & & & & & $-0.0214 * * *$ & -24.81 & $-0.227 \%$ & $-0.0214 * * *$ & -24.87 & $-0.227 \%$ & $-0.0046 * * *$ & -5.82 & $-0.230 \%$ & $-0.0045 * * *$ & -5.77 & $-0.231 \%$ \\
\hline $\mathrm{Age}^{2}$ & & & & & & & $0.031 * * *$ & -4.22 & - & $0.0317^{* * *}$ & 4.32 & - & $-0.0873 * * *$ & -13.03 & - & $-0.0878 * * *$ & -13.12 & - \\
\hline 10 Question Questionnaire & & & & & & & $-0.2281 * * *$ & -69.92 & $-2.913 \%$ & $-0.2282 * * *$ & -69.97 & $-2.918 \%$ & $-0.1834 * * *$ & -61.33 & $-2.860 \%$ & $-0.1834 * * *$ & -61.34 & $-2.868 \%$ \\
\hline Capacity & & & & & & & & & & & & & $0.6919 * * *$ & 137.58 & $10.712 \%$ & $0.6922 * * *$ & 137.63 & $10.740 \%$ \\
\hline Time & & & & & & & & & & & & & $0.1127 * * *$ & 30.69 & $1.701 \%$ & $0.1127^{* * *}$ & 30.68 & $1.702 \%$ \\
\hline Liquidity & & & & & & & & & & & & & $0.0417^{* * *}$ & 13.13 & $0.609 \%$ & $0.0418^{* * *}$ & 13.17 & $0.611 \%$ \\
\hline Capacity*Time*Liquidity & & & & & & & & & & & & & -0.0026 & -1.3 & - & -0.0027 & -1.35 & - \\
\hline Civil Partnership & & & & -0.0250 & -1.06 & $-0.252 \%$ & -0.012 & -0.52 & $-0.159 \%$ & 0.0538 & 1.55 & $-0.123 \%$ & -0.0232 & -1.09 & $-0.376 \%$ & 0.0133 & 0.42 & $-0.351 \%$ \\
\hline Married & & & & $-0.0927^{* * *}$ & -20.33 & $-0.997 \%$ & $0.0254 * * *$ & 5.54 & $0.328 \%$ & $0.0483^{* * *}$ & 7.15 & $0.340 \%$ & $0.0168^{* * *}$ & 4.01 & $0.264 \%$ & 0.0086 & 1.39 & $0.259 \%$ \\
\hline Divorced & & & & $-0.0872 * * *$ & -10.44 & $-0.934 \%$ & $0.0171^{* *}$ & 2.07 & $0.223 \%$ & $-0.0201 *$ & -1.83 & $0.441 \%$ & $0.0487 * * *$ & 6.47 & $0.747 \%$ & 0.0147 & 1.47 & $0.871 \%$ \\
\hline Widowed & & & & $-0.3184 * * *$ & -42.68 & $-4.038 \%$ & $0.0258^{* * *}$ & 3.31 & $0.333 \%$ & $0.0615^{* * *}$ & 6.54 & $0.004 \%$ & 0.0014 & 0.2 & $0.022 \%$ & $0.0212 * *$ & 2.42 & $-0.510 \%$ \\
\hline Civil Partnership * Male & & & & & & & & & & $-0.1113^{* *}$ & -2.4 & - & & & & -0.0617 & -1.46 & - \\
\hline Married * Male & & & & & & & & & & $-0.0389 * * *$ & -4.39 & - & & & & $0.0139 *$ & 1.71 & - \\
\hline Divorced $*$ Male & & & & & & & & & & $0.0962^{* * *}$ & 5.85 & - & & & & $0.075^{* * *}$ & 5.02 & - \\
\hline Widowed * Male & & & & & & & & & & $-0.1082 * * *$ & -6.56 & - & & & & $-0.0926 * * *$ & -6.14 & - \\
\hline Observations & 373,960 & & & 373,960 & & & 373,960 & & & 373,960 & & & 373,960 & & & 373,960 & & \\
\hline Time FE (Year) & Y & & & Y & & & Y & & & Y & & & Y & & & Y & & \\
\hline \ Predicted ATR (Male - Female) & 0.4790 & & & 0.4527 & & & 0.4511 & & & 0.4493 & & & 0.4090 & & & 0.4069 & & \\
\hline Pseudo $R^{2}$ & 0.00815 & & & 0.00936 & & & 0.0261 & & & 0.0262 & & & 0.0745 & & & 0.0746 & & \\
\hline
\end{tabular}


Table 6: Summary statistics of attitude to risk by gender and investment experience

This table reports summary statistics of attitude to risk and investment experience by gender over the sample period 1 January 2011 to 31 December 2016. Panel A represents the summary statistics of investment experience. Panel B shows the summary statistics of attitude to risk by gender and levels of investment experience. Investment Experience is the investor's level of experience in investing and is measured as a score variable (0-2) according to whether the investor is not experienced and has no financial knowledge, whether he/she has medium level of experience and financial literacy, or whether the she is comfortable in investing and understand potential financial risks and rewards. $*, * *$ and $* * *$ indicate significance at the $10 \%, 5 \%$ and $1 \%$ levels respectively

\begin{tabular}{ccccc}
\hline \multicolumn{4}{c}{ Panel A: Summary Statistics for Investment Experience } & \\
\hline All & Female & Male & $\begin{array}{c}\text { Diff. } \\
\text { (Female - Male) }\end{array}$ \\
\hline Mean & 0.949 & 0.866 & 1.009 & $-0.143^{* * *}$ \\
Median & 1.000 & 1.000 & 1.000 & 0.000 \\
Standard Deviation & 0.606 & 0.584 & 0.615 & - \\
Minimum & 0.000 & 0.000 & 0.000 & - \\
Maximum & 2.000 & 2.000 & 2.000 & - \\
No. of Observations & 42,005 & 17,609 & 24,396 & - \\
Percentage & $100.00 \%$ & $41.92 \%$ & $58.08 \%$ & \\
\hline
\end{tabular}

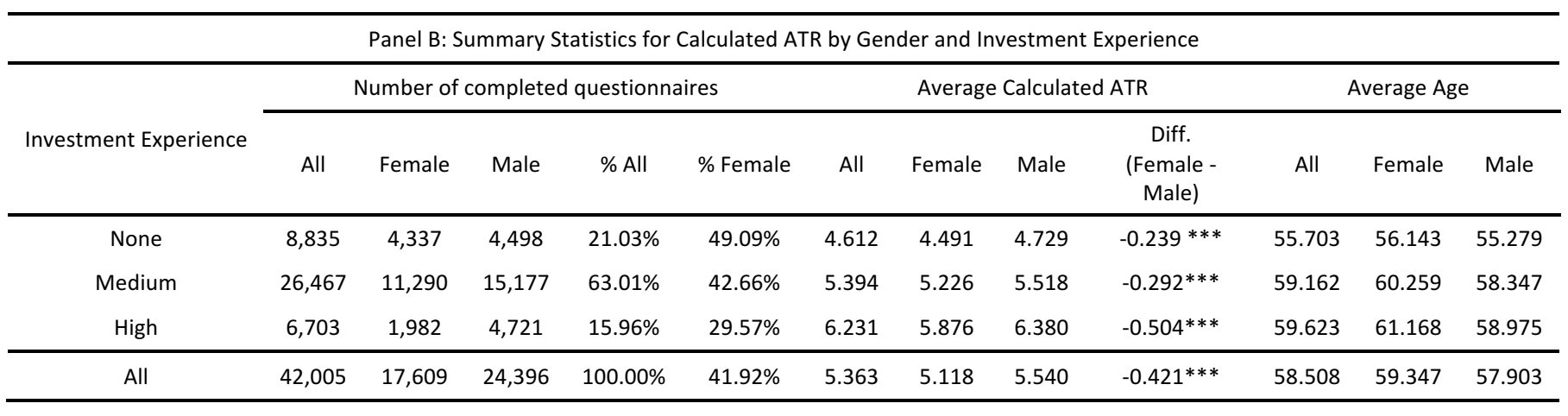




\section{Table 7: Attitude to risk, gender and investment experience - Ordered Probit regressions results}

This table reports the results of ordered probit regressions estimated with robust standard errors and time fixed effects (years). Period: 1 January 2011 - 31 December 2016. Other variable definitions and measurements are explained in the notes to Table 2. Investment Experience is the investor's level of experience in investing and is measured as a score variable (0-2) according to whether the investor is not experienced and has no financial knowledge, whether he/she has medium level of experience and financial literacy, or whether the she is comfortable in investing and understand potential financial risks and rewards. Z-tests are reported in parentheses. Marginal effects are reported in percentages. $*, * *$ and $* * *$ indicate significance at the $10 \%, 5 \%$ and $1 \%$ levels respectively.

\begin{tabular}{|c|c|c|c|c|c|}
\hline Dep. Var. Calculated ATR & (1) & (2) & (3) & (4) & (5) \\
\hline \multicolumn{6}{|l|}{ Ind. Variables: } \\
\hline \multirow[t]{3}{*}{ Male } & $0.3082 * * *$ & $0.1978 * * *$ & $0.0715^{* *}$ & $0.1940 * * *$ & $0.0602 * *$ \\
\hline & (30.98) & (21.59) & $(2.27)$ & $(22.66)$ & $(2.05)$ \\
\hline & $3.545 \%$ & $2.995 \%$ & $3.035 \%$ & $3.445 \%$ & $3.494 \%$ \\
\hline \multirow[t]{3}{*}{ Age } & & $-0.0237 * * *$ & $-0.0236 * * *$ & $-0.0085 * * *$ & $-0.0084 * * *$ \\
\hline & & $(-9.84)$ & $(-9.81)$ & $(-3.83)$ & $(-3.79)$ \\
\hline & & $-0.277 \%$ & $-0.277 \%$ & $-0.289 \%$ & $-0.290 \%$ \\
\hline \multirow[t]{3}{*}{ Age $^{2}$} & & $0.0465 * *$ & $0.0461 * *$ & $-0.0670 * * *$ & $-0.0674 * * *$ \\
\hline & & $(2.27)$ & $(2.25)$ & $(-3.55)$ & $(-3.58)$ \\
\hline & & - & - & - & - \\
\hline \multirow[t]{3}{*}{10 Question Questionnaire } & & $-0.1887 * * *$ & $-0.1883^{* * *}$ & $-0.1674 * * *$ & $-0.1671 * * *$ \\
\hline & & $(-20.82)$ & $(-20.79)$ & $(-19.78)$ & $(-19.74)$ \\
\hline & & $-2.857 \%$ & $-2.863 \%$ & $-2.974 \%$ & $-2.980 \%$ \\
\hline \multirow[t]{3}{*}{ Capacity } & & & & $0.6050 * * *$ & $0.6060 * * *$ \\
\hline & & & & $(42.05)$ & $(42.12)$ \\
\hline & & & & $10.859 \%$ & $10.908 \%$ \\
\hline \multirow[t]{3}{*}{ Time } & & & & $0.1045^{* * *}$ & $0.1048 * * *$ \\
\hline & & & & $(10.23)$ & $(10.26)$ \\
\hline & & & & $1.936 \%$ & $1.941 \%$ \\
\hline \multirow[t]{3}{*}{ Liquidity } & & & & $0.0318^{* * *}$ & $0.0316^{* * *}$ \\
\hline & & & & $(3.58)$ & (3.57) \\
\hline & & & & $0.623 \%$ & $0.617 \%$ \\
\hline \multirow[t]{3}{*}{ Capacity*Time*Liquidity } & & & & 0.0032 & 0.0029 \\
\hline & & & & $(0.58)$ & $(0.52)$ \\
\hline & & & & - & - \\
\hline \multirow[t]{3}{*}{ Investment Experience } & & $0.6062^{* * *}$ & $0.5663 * * *$ & $0.4671 * * *$ & $0.4248 * * *$ \\
\hline & & $(74.16)$ & $(45.95)$ & $(59.93)$ & (36.51) \\
\hline & & $9.180 \%$ & $9.189 \%$ & $8.295 \%$ & $8.297 \%$ \\
\hline \multirow[t]{3}{*}{ Investment Experience* Male } & & & $0.0657^{* * *}$ & & $0.0696 * * *$ \\
\hline & & & $(4.17)$ & & $(4.75)$ \\
\hline & & & - & & - \\
\hline Observations & 42,005 & 42,005 & 42,005 & 42,005 & 42,005 \\
\hline Time FE (Year) & Y & Y & Y & Y & Y \\
\hline$\Delta$ Predicted ATR (Male - Female) & 0.4204 & 0.2697 & 0.2722 & 0.2644 & 0.2671 \\
\hline Pseudo $\mathrm{R}^{2}$ & 0.0064 & 0.0608 & 0.0609 & 0.0998 & 0.0999 \\
\hline
\end{tabular}




\section{Table 8: Attitude to risk, gender, age, risk financial capacity, demographics and investment experience (summary) - Ordered Probit regressions results}

This table reports the results of ordered probit regressions estimated with robust standard errors and time fixed effects (years). Period: 1 January 2011 - 31 December 2016. Other variable definitions and measurements are explained in previous tables. Z-tests are reported (z). ${ }^{* * *}$ and $* * *$ indicate significance at the $10 \%, 5 \%$ and $1 \%$ levels respectively

\begin{tabular}{|c|c|c|c|c|c|c|c|c|c|c|c|c|c|c|}
\hline \multirow{2}{*}{ Dep. Var. Calculated ATR } & \multicolumn{2}{|l|}{ (1) } & \multicolumn{2}{|c|}{ (2) } & \multicolumn{2}{|c|}{ (3) } & \multicolumn{2}{|c|}{ (4) } & \multicolumn{2}{|l|}{ (5) } & \multicolumn{2}{|l|}{ (6) } & \multicolumn{2}{|c|}{ (7) } \\
\hline & Coeff. & $\mathrm{z}$ & Coeff. & $\mathrm{z}$ & Coeff. & $\mathrm{z}$ & Coeff. & $\mathrm{z}$ & Coeff. & $\mathrm{z}$ & Coeff. & $\mathrm{z}$ & Coeff. & $\mathrm{z}$ \\
\hline \multicolumn{15}{|l|}{ Ind. Variables: } \\
\hline Male & $0.3169 * * *$ & 8.08 & $0.2841 * * *$ & 7.54 & $0.2566 * * *$ & 7.33 & $0.2214 * * *$ & 6.19 & $0.2251 * * *$ & 6.23 & $0.1576 * * *$ & 4.54 & -0.0422 & -0.61 \\
\hline Age & & & $-0.0425 * * *$ & -3.91 & $-0.0240 * *$ & -2.37 & $-0.0248^{* *}$ & -2.52 & $-0.0231 * *$ & -2.26 & $-0.0221 * *$ & -2.29 & $-0.0213^{* *}$ & -2.18 \\
\hline $\mathrm{Age}^{2}$ & & & $0.2018^{* *}$ & 2.24 & 0.0585 & 0.70 & 0.0826 & 1.00 & 0.0657 & 0.77 & 0.0362 & 0.44 & 0.0307 & 0.37 \\
\hline 10 Question Questionnaire & & & $-0.3097 * * *$ & -8.01 & $-0.2618^{* * *}$ & -7.35 & $-0.2591 * * *$ & -7.30 & $-0.2647 * * *$ & -7.46 & $-0.2417 * * *$ & -7.16 & $-0.2383 * * *$ & -7.07 \\
\hline Capacity & & & & & $0.7767 * * *$ & 12.29 & $0.7600^{* * *}$ & 12.20 & $0.7606^{* * *}$ & 12.19 & $0.6153^{* * *}$ & 10.48 & $0.6168^{* * *}$ & 10.51 \\
\hline Time & & & & & $0.1152^{* *}$ & 2.48 & $0.1147^{* *}$ & 2.47 & $0.1144^{* *}$ & 2.46 & $0.0868 *$ & 1.96 & $0.0830 *$ & 1.87 \\
\hline Liquidity & & & & & 0.0367 & 0.93 & 0.0267 & 0.68 & 0.0237 & 0.60 & -0.0591 & -1.54 & -0.0585 & -1.52 \\
\hline Capacity*Time*Liquidity & & & & & -0.0207 & -0.85 & -0.0174 & -0.71 & -0.0176 & -0.72 & -0.0043 & -0.19 & -0.0047 & -0.20 \\
\hline Director or Partner & & & & & & & $0.4376^{* * *}$ & 4.50 & $0.4331 * * *$ & 4.47 & $0.3467^{* * *}$ & 3.90 & $0.3427^{* * *}$ & 3.88 \\
\hline Employed/Self Employed & & & & & & & $0.4027^{* * *}$ & 2.85 & $0.3986^{* * *}$ & 2.83 & $0.3635^{* * *}$ & 2.79 & $0.3794 * * *$ & 2.92 \\
\hline Self Employed & & & & & & & $0.1645^{* *}$ & 2.31 & $0.1615^{* *}$ & 2.26 & $0.1590 * *$ & 2.33 & $0.1640 * *$ & 2.41 \\
\hline Employed & & & & & & & 0.0189 & 0.37 & 0.0164 & 0.32 & 0.0291 & 0.59 & 0.0314 & 0.64 \\
\hline House-Person & & & & & & & -0.1106 & -0.85 & -0.0922 & -0.70 & -0.0962 & -0.72 & -0.1008 & -0.76 \\
\hline Semi-Retired & & & & & & & $0.2618^{* *}$ & 2.05 & $0.2547 * *$ & 1.98 & 0.1718 & 1.42 & 0.1620 & 1.35 \\
\hline Non-Working & & & & & & & -0.1992 & -1.61 & -0.1969 & -1.60 & -0.1144 & -0.96 & -0.0853 & -0.72 \\
\hline Civil Partnership & & & & & & & & & $-0.5433 * * *$ & -3.26 & $-0.623 * * *$ & -3.18 & $-0.6234 * * *$ & -3.07 \\
\hline Married & & & & & & & & & -0.0492 & -1.08 & -0.0401 & -0.93 & -0.0374 & -0.87 \\
\hline Divorced & & & & & & & & & -0.0542 & -0.69 & -0.0726 & -1.00 & -0.0837 & -1.15 \\
\hline Widowed & & & & & & & & & 0.0119 & 0.16 & 0.0353 & 0.49 & 0.0439 & 0.61 \\
\hline Investment Experience & & & & & & & & & & & $0.4946^{* * *}$ & 16.69 & $0.3733^{* * *}$ & 8.53 \\
\hline Investment Experience*Male & & & & & & & & & & & & & $0.1981 * * *$ & 3.53 \\
\hline Observations & 2,669 & & 2,669 & & 2,669 & & 2,669 & & 2,669 & & 2,669 & & 2,669 & \\
\hline Time FE (Year) & Y & & Y & & Y & & Y & & Y & & Y & & Y & \\
\hline$\Delta$ Predicted ATR (Male - Female) & 0.4299 & & 0.3858 & & 0.3488 & & 0.3011 & & 0.3060 & & 0.2150 & & 0.2211 & \\
\hline Pseudo $\mathrm{R}^{2}$ & 0.0070 & & 0.0316 & & 0.0798 & & 0.0844 & & 0.0849 & & 0.115 & & 0.116 & \\
\hline
\end{tabular}




\section{Figure 3: Attitude to risk - Adjustment (Selected ATR - Calculated ATR)}

This figure shows the average difference between the attitude to risk which is selected after the discussion between the client and the financial advisor (Selected ATR), and the attitude to risk calculated from the risk profiling questionnaire (Calculated ATR), for female and male clients, over the period from 1 January 2011 to 31 December 2016. Panel A reports the relationship between the ATR Adjustment, which is the difference between the Selected ATR and the Calculated ATR and it is measured in integer scores from -9 to 9 , and the Calculated ATR of a client; Panel B shows the relationship between the Absolute ATR Adjustment, which is the absolute difference between the Selected ATR and the Calculated ATR and is measured in integer scores from 0 to 9 , and the Calculated ATR of a client.

Panel A: ATR Adjustment, (Selected ATR - Calculated ATR)

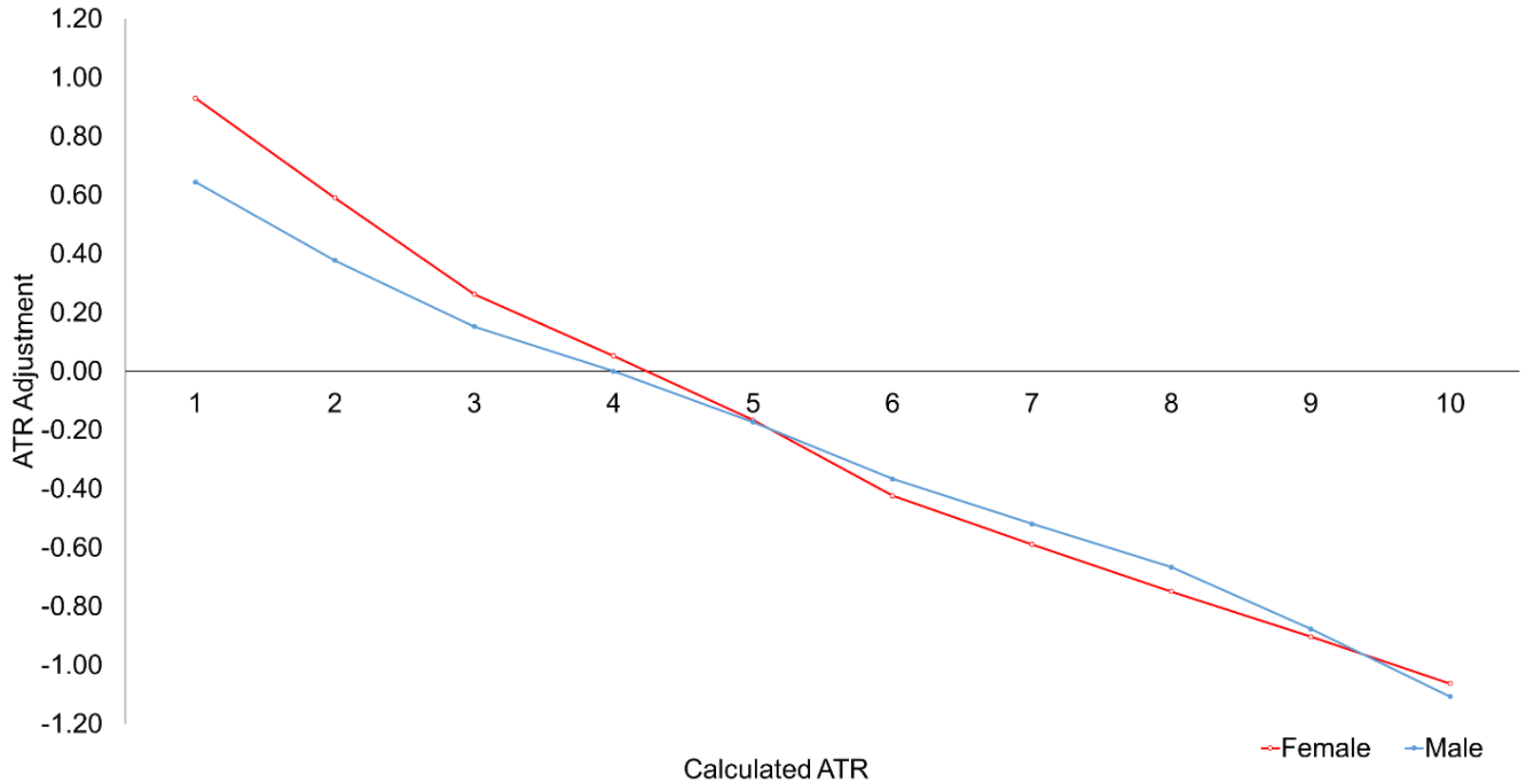

Panel B: Absolute ATR Adjustment, |Selected ATR - Calculated ATR |

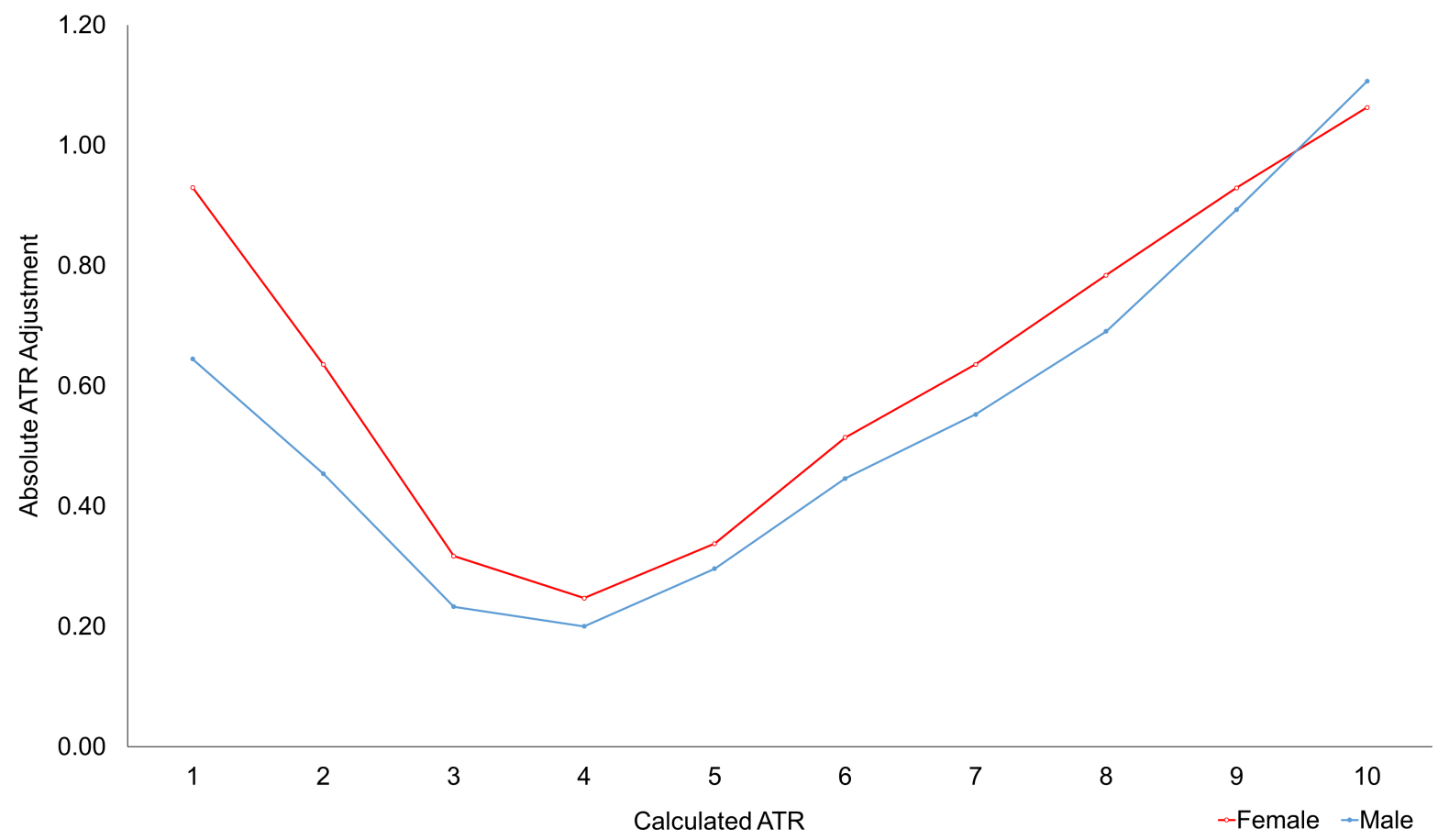




\section{Table 9: Attitude to risk - Adjustment}

This table reports the ATR Adjustment and the Absolute ATR Adjustment by gender over the sample period from 1 January 2011 to 31 December 2016. The ATR Adjustment is the difference between the Selected ATR and the Calculated ATR and it is measured in integer scores from -9 to 9 . The Absolute ATR Adjustment is the absolute difference between the Selected ATR and the Calculated ATR and it is measured in integer scores from 0 to 9 , and the Calculated ATR of a client. Panel A reports the number of completed questionnaires by Calculated ATR score; Panel B shows the average ATR Adjustment and Absolute ATR by gender and Calculated ATR score. *, ** and *** indicate significance at the $10 \%$, $5 \%$ and $1 \%$ levels respectively.

\begin{tabular}{cccccc}
\hline \multicolumn{5}{c}{ Panel A: Number of completed questionnaires by Calculated ATR } \\
\hline Scores & All & Female & Male & $\%$ All & \%Female \\
\hline 1 & 2,309 & 1,169 & 1,140 & $0.43 \%$ & $50.63 \%$ \\
2 & 8,439 & 4,630 & 3,809 & $1.58 \%$ & $54.86 \%$ \\
3 & 39,119 & 20,532 & 18,587 & $7.33 \%$ & $52.49 \%$ \\
4 & 99,392 & 50,200 & 49,192 & $18.63 \%$ & $50.51 \%$ \\
5 & 143,440 & 65,876 & 77,564 & $26.89 \%$ & $45.93 \%$ \\
6 & 127,847 & 49,555 & 78,292 & $23.96 \%$ & $38.76 \%$ \\
7 & 79,981 & 24,456 & 55,525 & $14.99 \%$ & $30.58 \%$ \\
8 & 25,630 & 5,905 & 19,725 & $4.80 \%$ & $23.04 \%$ \\
9 & 5,638 & 1,061 & 4,577 & $1.06 \%$ & $18.82 \%$ \\
10 & 1,723 & 317 & 1,406 & $0.32 \%$ & $18.40 \%$ \\
\hline All Scores & 533,518 & 223,701 & 309,817 & $100.00 \%$ & $41.93 \%$ \\
\hline
\end{tabular}

\begin{tabular}{|c|c|c|c|c|c|c|c|c|}
\hline \multirow{3}{*}{ Scores } & \multicolumn{7}{|c|}{ Panel B: Mean ATR Adjustment by Calculated ATR } & \\
\hline & \multicolumn{4}{|c|}{$\begin{array}{c}\text { ATR Adjustment } \\
\text { (Selected ATR - Calculated ATR) }\end{array}$} & \multicolumn{4}{|c|}{$\begin{array}{c}\text { Absolute ATR Adjustment } \\
\text { |Selected ATR - Calculated ATR/ }\end{array}$} \\
\hline & All & Female & Male & $\begin{array}{c}\text { Difference } \\
\text { (Female-Male) }\end{array}$ & All & Female & Male & $\begin{array}{c}\text { Diff. } \\
\text { (Female - Male) }\end{array}$ \\
\hline 1 & 0.789 & 0.930 & 0.645 & $0.285^{* * *}$ & 0.789 & 0.930 & 0.645 & $0.285^{* * *}$ \\
\hline 2 & 0.495 & 0.591 & 0.378 & $0.213^{* * *}$ & 0.554 & 0.636 & 0.454 & $0.182^{* * *}$ \\
\hline 3 & 0.210 & 0.263 & 0.152 & $0.110 * * *$ & 0.277 & 0.317 & 0.233 & $0.084 * * *$ \\
\hline 4 & 0.027 & 0.053 & 0.000 & $0.052 * * *$ & 0.224 & 0.247 & 0.200 & $0.047 * * *$ \\
\hline 5 & -0.170 & -0.166 & -0.173 & $0.007^{*}$ & 0.315 & 0.338 & 0.296 & $0.042 * * *$ \\
\hline 6 & -0.389 & -0.424 & -0.366 & $-0.057^{* * *}$ & 0.473 & 0.514 & 0.446 & $0.068^{* * *}$ \\
\hline 7 & -0.540 & -0.589 & -0.519 & $-0.070 * * *$ & 0.578 & 0.636 & 0.553 & $0.083^{* * *}$ \\
\hline 8 & -0.685 & -0.749 & -0.666 & $-0.083^{* * *}$ & 0.712 & 0.784 & 0.691 & $0.093 * * *$ \\
\hline 9 & -0.882 & -0.903 & -0.877 & -0.026 & 0.900 & 0.929 & 0.893 & 0.036 \\
\hline 10 & -1.099 & -1.063 & -1.107 & 0.044 & 1.099 & 1.063 & 1.107 & -0.044 \\
\hline All Scores & -0.234 & -0.180 & -0.273 & $0.093 * * *$ & 0.406 & 0.412 & 0.402 & $0.010 * * *$ \\
\hline
\end{tabular}




\section{Table 10: ATR Adjustment and Gender - Ordered Probit regressions results}

This table reports the results of ordered probit regressions estimated with robust standard errors and time fixed effects (years). Period: 1 January 2011 - 31 December 2016. Other variable definitions and measurements are explained in the notes to Table 2 . The dependent variable is an integer score variable which takes values $-1,0$ and 1 according to whether the ATR adjustment is negative, null or positive, and measures the sign of the ATR adjustment. Male, ATR $<=4$ and Male, ATR $>=\mathbf{6}$ are two dummy variables equal to one when the client is Male and his Calculated ATR is smaller than or equal to 4 , or greater than or equal to 6 , respectively. Female, $A T R<=4$ and Female, $A T R>=6$ are two dummy variables equal to one when the client is Female and her Calculated ATR is smaller than or equal to 4, or greater than or equal to 6 , respectively. Z-tests are reported in parentheses. Marginal effects are reported in percentages. $*, * *$ and $* * *$ indicate significance at the $10 \%, 5 \%$ and $1 \%$ levels respectively.

\begin{tabular}{|c|c|c|c|c|c|}
\hline \multirow{2}{*}{ Dep.Var. } & \multicolumn{5}{|c|}{ ATR Adjustment $\{-1,0,+1\}$} \\
\hline & (1) & (2) & (3) & (4) & (5) \\
\hline \multicolumn{6}{|l|}{ Ind. Variables: } \\
\hline \multirow[t]{3}{*}{ Male } & $-0.1260 * * *$ & -0.0060 & $-0.1374 * * *$ & $-0.0147 * *$ & $-0.0121^{*}$ \\
\hline & $(-37.14)$ & $(-0.96)$ & $(-40.40)$ & $(-2.37)$ & $(-1.96)$ \\
\hline & $-1.514 \%$ & $-0.064 \%$ & $-1.630 \%$ & $-0.152 \%$ & $-0.125 \%$ \\
\hline \multirow{3}{*}{ Male, ATR $<=4$} & & $0.4552 * * *$ & & $0.4816 * * *$ & $0.5191 * * *$ \\
\hline & & (78.89) & & $(83.83)$ & (89.69) \\
\hline & & $4.837 \%$ & & $4.985 \%$ & $5.359 \%$ \\
\hline \multirow[t]{3}{*}{ Female, ATR $<=4$} & & $0.5730 * * *$ & & $0.5950 * * *$ & $0.6305^{* * *}$ \\
\hline & & $(89.00)$ & & (92.95) & $(97.98)$ \\
\hline & & $6.089 \%$ & & $6.158 \%$ & $6.509 \%$ \\
\hline \multirow[t]{3}{*}{ Male, ATR $>=6$} & & $-0.3568 * * *$ & & $-0.4099 * * *$ & $-0.4432 * * *$ \\
\hline & & $(-71.12)$ & & $(-81.96)$ & $(-87.73)$ \\
\hline & & $-3.792 \%$ & & $-4.242 \%$ & $-4.575 \%$ \\
\hline \multirow[t]{3}{*}{ Female, ATR $>=6$} & & $-0.4094 * * *$ & & $-0.4574 * * *$ & $-0.0100 * * *$ \\
\hline & & $(-64.38)$ & & $(-72.41)$ & $(-76.48)$ \\
\hline & & $-4.351 \%$ & & $-4.734 \%$ & $-5.003 \%$ \\
\hline \multirow[t]{3}{*}{ Age } & & & $-0.0102 * * *$ & $-0.0135 * * *$ & $-0.0101 * * *$ \\
\hline & & & $(-13.11)$ & $(-17.91)$ & $(-13.31)$ \\
\hline & & & $-0.081 \%$ & $-0.130 \%$ & $-0.120 \%$ \\
\hline \multirow[t]{3}{*}{ Age $^{2}$} & & & $0.0292^{* * *}$ & 0.0084 & $-0.0133 * *$ \\
\hline & & & $(4.28)$ & $(1.28)$ & $(-2.02)$ \\
\hline & & & - & - & - \\
\hline \multirow{3}{*}{$\begin{array}{l}10 \text { Question } \\
\text { Questionnaire }\end{array}$} & & & $0.0642^{* * *}$ & $-0.0268 * * *$ & $-0.0261 * * *$ \\
\hline & & & $(19.29)$ & $(-8.44)$ & $(-8.23)$ \\
\hline & & & $0.762 \%$ & $-0.278 \%$ & $-0.269 \%$ \\
\hline \multirow[t]{3}{*}{ Capacity } & & & & & $0.1172 * * *$ \\
\hline & & & & & $(23.45)$ \\
\hline & & & & & $1.291 \%$ \\
\hline \multirow[t]{3}{*}{ Time } & & & & & $0.0658 * * *$ \\
\hline & & & & & $(18.28)$ \\
\hline & & & & & $0.735 \%$ \\
\hline \multirow[t]{3}{*}{ Liquidity } & & & & & $-0.0279 * * *$ \\
\hline & & & & & $(-8.87)$ \\
\hline & & & & & $-0.247 \%$ \\
\hline \multirow[t]{3}{*}{ Capacity*Time*Liquidity } & & & & & $0.0039 * *$ \\
\hline & & & & & $(2.06)$ \\
\hline & & & & & - \\
\hline Observations & 533,518 & 533,518 & 533,518 & 533,518 & 533,518 \\
\hline Time FE (Year) & $\mathrm{Y}$ & $\mathrm{Y}$ & Y & Y & Y \\
\hline Pseudo $\mathrm{R}^{2}$ & 0.00325 & 0.0668 & 0.00734 & 0.0796 & 0.0828 \\
\hline
\end{tabular}


Table11: "Who Wins" within Married Couples? - Number of Questionnaires.

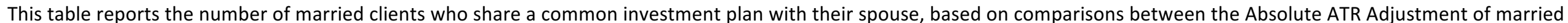

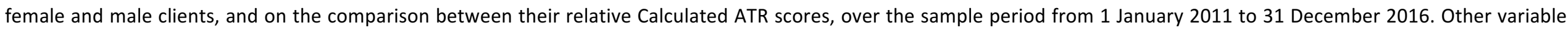

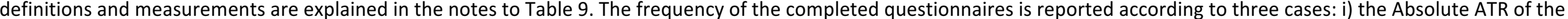

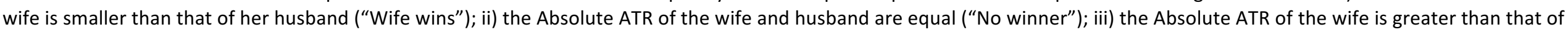
her husband ("Husband wins").

\begin{tabular}{|c|c|c|c|c|c|c|c|c|c|}
\hline \multicolumn{10}{|c|}{ Panel A: 'Who Wins?': Number and Percentage of Cases that Each Gender Wins } \\
\hline & \multirow{2}{*}{$\begin{array}{c}\text { Number of } \\
\text { completed } \\
\text { questionnaire } \\
s\end{array}$} & \multirow[t]{2}{*}{ \%Couples } & \multicolumn{3}{|c|}{$\begin{array}{c}\text { Abs. Adjustment Female } \\
< \\
\text { Abs. Adjustment Male } \\
\text { (Wife wins) }\end{array}$} & \multicolumn{2}{|c|}{$\begin{array}{l}\text { Abs. Adjustment Female } \\
= \\
\text { Abs. Adjustment Male } \\
\text { (No winner) }\end{array}$} & \multicolumn{2}{|c|}{$\begin{array}{l}\text { Abs. Adjustment Female } \\
> \\
\text { Abs. Adjustment Male } \\
\text { (Husband wins) }\end{array}$} \\
\hline & & & Obs & & $\%$ Adj. & Obs & $\%$ Adj. & Obs & $\%$ Adj. \\
\hline $\begin{array}{c}\text { Calc.ATR Female }>\text { Calc.ATR } \\
\text { Male }\end{array}$ & 4,702 & $7.603 \%$ & 1,335 & & $28.39 \%$ & 350 & $7.44 \%$ & 3,017 & $64.16 \%$ \\
\hline $\begin{array}{c}\text { Calc.ATR Female }=\text { Calc.ATR } \\
\text { Male }\end{array}$ & 42,330 & $68.451 \%$ & - & & - & 42,330 & $100.00 \%$ & - & - \\
\hline $\begin{array}{c}\text { Calc.ATR Female }<\text { Calc.ATR } \\
\text { Male }\end{array}$ & 14,808 & $23.946 \%$ & 7,465 & & $50.41 \%$ & 1,645 & $11.11 \%$ & 5,698 & $38.48 \%$ \\
\hline Couples & 61,840 & $\begin{array}{c}100.000 \\
\%\end{array}$ & 8,800 & & $14.23 \%$ & 44,325 & $71.68 \%$ & 8,715 & $14.09 \%$ \\
\hline \multicolumn{10}{|c|}{ Panel B: Table of Actual Numbers } \\
\hline & Wife Wins & & Husband Wins & & Total & & & & \\
\hline Female $>$ Male & 1,335 & $30.7 \%$ & 3,017 & $69.3 \%$ & 4,352 & & & & \\
\hline Female $<$ Male & 7,465 & $56.7 \%$ & 5,698 & $43.3 \%$ & 13,163 & & & & \\
\hline Total & 8,800 & & 8,715 & & 17,515 & & & & \\
\hline \multicolumn{10}{|c|}{ Panel C: Table of Expected Numbers } \\
\hline & Wife Wins & & Husband Wins & & Total & & & & \\
\hline Female $>$ Male & 2,187 & $50.2 \%$ & 2,165 & $49.8 \%$ & 4,352 & & & & \\
\hline Female $<$ Male & 6,613 & $50.2 \%$ & 6,550 & $49.8 \%$ & 13,163 & & & & \\
\hline Total & 8,800 & & 8,715 & & & & & & \\
\hline
\end{tabular}


Panel D: 'Who Wins?' Average Absolute ATR Adjustments

\begin{tabular}{|c|c|c|c|c|c|c|c|c|c|}
\hline & \multicolumn{3}{|c|}{$\begin{array}{l}\text { Abs. Adjustment Female } \\
< \\
\text { Abs. Adjustment Male } \\
\text { (Wife wins) }\end{array}$} & \multicolumn{3}{|c|}{$\begin{array}{l}\text { Abs. Adjustment Female } \\
= \\
\text { Abs. Adjustment Male } \\
\text { (No winner) }\end{array}$} & \multicolumn{3}{|c|}{$\begin{array}{l}\text { Abs. Adjustment Female } \\
> \\
\text { Abs. Adjustment Male } \\
\text { (Husband wins) }\end{array}$} \\
\hline & Female & Male & Diff & Female & Male & Diff & Female & Male & Diff \\
\hline Calc.ATR Female $>$ Calc.ATR Male & 0.1378 & 1.3341 & -1.1963 & 1.0371 & 1.0371 & 0.0000 & 1.4226 & 0.2565 & 1.1661 \\
\hline Calc.ATR Female $=$ Calc.ATR Male & - & - & - & 0.3951 & 0.3951 & 0.0000 & - & - & - \\
\hline Calc.ATR Female < Calc.ATR Male & 0.3060 & 1.6317 & -1.3258 & 1.1015 & 1.1015 & 0.0000 & 1.6558 & 0.1578 & 1.4981 \\
\hline Couples & 0.2805 & 1.5866 & -1.3061 & 0.4264 & 0.4264 & 0.0000 & 1.5751 & 0.1920 & 1.3831 \\
\hline
\end{tabular}




\section{Table 12: "Who Wins" within Married Couples? - Summary Statistics}

This table reports summary statistics of the attitude to risk and ATR adjustment of married clients with investment plan not in common with their spouse (Single Plan), and for married clients with investment plan in common with their spouse (Joint Plan), by gender over the sample period from 1 January 2011 to 31 December 2016. Other variable definitions and measurements are explained in the notes to Table 9. Panel A reports summary statistics for the Calculated ATR and Selected ATR, for married clients with single and joint plans, and by gender; Panel B shows the ATR Adjustment and the Absolute ATR Adjustment for married clients with single and joint plans, and by gender; Panel $C$ shows the number of completed questionnaires over time, for married clients with single and joint plans, and by gender. $*, * *$ and $* * *$ indicate significance at the $10 \%, 5 \%$ and $1 \%$ levels respectively.

Panel A: Calculated ATR and Selected ATR for Married Couples of Investors with Single Plans or Joint Plans

\begin{tabular}{|c|c|c|c|c|c|c|c|c|}
\hline \multirow{3}{*}{ Advisory } & \multicolumn{4}{|c|}{ Calculated ATR } & \multicolumn{4}{|c|}{ Selected ATR } \\
\hline & \multicolumn{2}{|c|}{ Married Female } & \multicolumn{2}{|c|}{ Married Male } & \multicolumn{2}{|c|}{ Married Female } & \multicolumn{2}{|c|}{ Married Male } \\
\hline & Single Plan & Joint Plan & Single Plan & Joint Plan & Single Plan & Joint Plan & Single Plan & Joint Plan \\
\hline Mean & 5.117 & 5.060 & 5.614 & 5.350 & 4.930 & 4.952 & 5.359 & 4.952 \\
\hline Median & 5 & 5 & 6 & 5 & 5 & 5 & 5 & 5 \\
\hline Standard Deviation & 1.384 & 1.350 & 1.481 & 1.392 & 1.348 & 1.308 & 1.470 & 1.308 \\
\hline Minimum & 1 & 1 & 1 & 1 & 1 & 1 & 1 & 1 \\
\hline Maximum & 10 & 10 & 10 & 10 & 10 & 10 & 10 & 10 \\
\hline No. of Observations & 51,385 & 61,840 & 106,834 & 61,840 & 51,385 & 61,840 & 106,834 & 61,840 \\
\hline Test for Mean Difference & \multicolumn{2}{|c|}{$0.057 * * *$} & \multicolumn{2}{|c|}{$0.263 * * *$} & \multicolumn{2}{|c|}{$-0.022 * * *$} & \multicolumn{2}{|c|}{$0.407 * * *$} \\
\hline
\end{tabular}

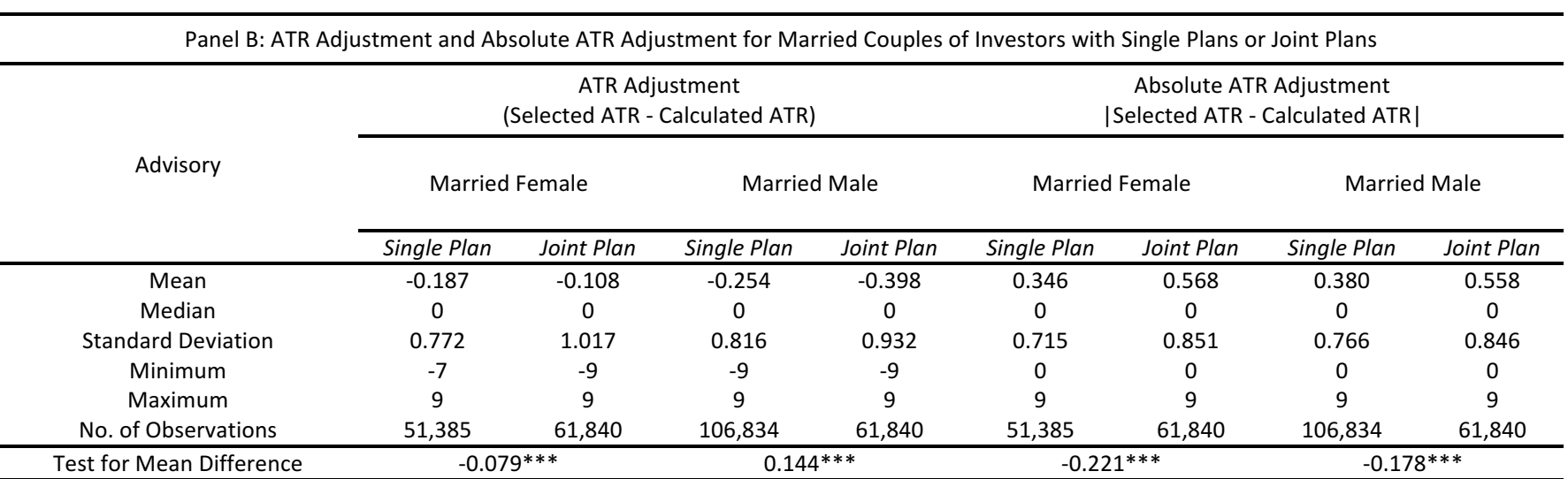

Panel C :Married Couples over Time

\begin{tabular}{ccccc}
\hline \multicolumn{3}{c}{ Number of completed questionnaires } & & Percentage of completed questionnaires \\
\cline { 2 - 5 } Year & $\begin{array}{c}\text { Married Couples with } \\
\text { Single Plan }\end{array}$ & $\begin{array}{c}\text { Married Couples with } \\
\text { Joint Plan }\end{array}$ & $\begin{array}{c}\text { Known Marital } \\
\text { Status }\end{array}$ & $\begin{array}{c}\text { Married Couples with } \\
\text { Joint Plan / Total Married } \\
\text { Couples }\end{array}$ \\
\hline 2011 & 11,714 & 5,139 & 36,521 & $30.49 \%$ \\
2012 & 17,938 & 6,218 & 44,096 & $25.74 \%$ \\
2013 & 21,711 & 9,045 & 56,615 & $29.41 \%$ \\
2014 & 28,044 & 12,330 & 73,668 & $30.54 \%$ \\
2015 & 35,467 & 14,088 & 89,188 & $28.43 \%$ \\
2016 & 43,345 & 15,020 & $14.07 \%$ & $25.73 \%$ \\
\hline All & 158,219 & 61,840 & 103,181 & $15 \%$ \\
\hline
\end{tabular}




\section{Table 13: "Who Wins" within Married Couples? - Ordered Probit regressions results}

This table reports the results of ordered probit regressions estimated with robust standard errors and time fixed effects (years). Period: 1 January 2011 - 31 December 2016. The dependent variable is an integer score variable which takes values $-1,0$ and 1 according to whether the absolute ATR adjustment of the wife is greater than (winning husband), equal to (no winner), or smaller than (winning wife) the absolute ATR adjustment of her husband. Riskier Wife is a binary variable equal to 1 when the Calculated ATR of the wife is greater than the Calculated ATR of her husband. Riskier Husband is a binary variable equal to 1 when the Calculated ATR of the husband is greater than the Calculated ATR of his spouse. Age Spread (F-M) is the difference between the age (measured in years) of the wife and the age of her husband. Other variables are measured as simple averages between the variables of the two spouses. Definitions and measurements are explained in the notes to Table 2. Z-tests are reported in parentheses. Marginal effects are reported in percentages. $*, * *$ and $* * *$ indicate significance at the $10 \%, 5 \%$ and $1 \%$ levels respectively.

\begin{tabular}{|c|c|c|c|c|c|c|}
\hline \multirow{2}{*}{ Dep.Var. } & \multicolumn{6}{|c|}{ Winning Wife $\{-1,0,+1\}$} \\
\hline & (1) & $(2)$ & (3) & (4) & (5) & (6) \\
\hline \multicolumn{7}{|l|}{ Ind. Variables: } \\
\hline \multirow[t]{3}{*}{ Age } & $0.0093 * *$ & & $0.0097 * * *$ & & 0.0093 & $0.0096 * * * *$ \\
\hline & $(2.47)$ & & $(2.61)$ & & $(2.47)$ & (2.58) \\
\hline & $0.042 \%$ & & $0.049 \%$ & & $0.042 \%$ & $0.049 \%$ \\
\hline \multirow[t]{3}{*}{ Age $^{2}$} & $-0.0603 * *$ & & $-0.0614^{* *}$ & & -0.0603 & $-0.0605^{* *}$ \\
\hline & $(-2.01)$ & & $(-2.07)$ & & $(-2.01)$ & $(-2.04)$ \\
\hline & - & & - & & - & - \\
\hline \multirow[t]{3}{*}{10 Question Questionnaire } & 0.0036 & & $0.0174 *$ & & 0.0036 & $0.0175^{*}$ \\
\hline & $(0.36)$ & & (1.79) & & $(0.36)$ & $(1.80)$ \\
\hline & $0.081 \%$ & & $0.394 \%$ & & $0.081 \%$ & $0.397 \%$ \\
\hline \multirow[t]{3}{*}{ Capacity } & $0.056 * * *$ & & $0.0465 * * *$ & & 0.056 & $0.0464 * * *$ \\
\hline & $(3.45)$ & & $(2.91)$ & & $(3.45)$ & $(2.90)$ \\
\hline & $1.082 \%$ & & $0.810 \%$ & & $1.082 \%$ & $0.812 \%$ \\
\hline \multirow[t]{3}{*}{ Time } & -0.0092 & & -0.0085 & & -0.0092 & -0.0085 \\
\hline & $(-0.69)$ & & $(-0.64)$ & & $(-0.69)$ & $(-0.64)$ \\
\hline & $-0.346 \%$ & & $-0.378 \%$ & & $-0.346 \%$ & $-0.374 \%$ \\
\hline \multirow[t]{3}{*}{ Liquidity } & 0.0109 & & 0.0086 & & 0.0109 & 0.0086 \\
\hline & $(1.00)$ & & $(0.81)$ & & $(1.00)$ & $(0.81)$ \\
\hline & $0.153 \%$ & & $0.071 \%$ & & $0.154 \%$ & $0.073 \%$ \\
\hline \multirow[t]{3}{*}{ Capacity*Time*Liquidity } & -0.0042 & & -0.0056 & & -0.0042 & -0.0055 \\
\hline & $(-0.60)$ & & $(-0.81)$ & & $(-0.60)$ & $(-0.80)$ \\
\hline & - & & - & & - & - \\
\hline \multirow[t]{3}{*}{ Riskier Wife } & & $-0.7463 * * *$ & $-0.7357 * * *$ & & & $-0.7358 * * *$ \\
\hline & & $(-25.99)$ & $(-25.59)$ & & & $(-25.59)$ \\
\hline & & $-16.738 \%$ & $-16.653 \%$ & & & $-16.654 \%$ \\
\hline \multirow[t]{3}{*}{ Riskier Husband } & & $0.2502^{* * *}$ & $0.2608^{* * *}$ & & & $0.2613^{* * *}$ \\
\hline & & $(15.81)$ & $(16.36)$ & & & (16.39) \\
\hline & & $5.612 \%$ & $5.904 \%$ & & & $5.914 \%$ \\
\hline \multirow[t]{3}{*}{ Age Spread (F - M) } & & & & -0.0003 & -0.0001 & -0.0015 \\
\hline & & & & $(-0.23)$ & $(-0.06)$ & $(-1.41)$ \\
\hline & & & & $-0.006 \%$ & $-0.001 \%$ & $-0.034 \%$ \\
\hline Observations & 58,530 & 58,530 & 58,530 & 58,530 & 58,530 & 58,530 \\
\hline Time FE (Year) & $\mathrm{Y}$ & Y & $\mathrm{Y}$ & $Y$ & $\mathrm{Y}$ & $\mathrm{Y}$ \\
\hline Pseudo $\mathrm{R}^{2}$ & 0.0009 & 0.0297 & 0.0303 & 0.0003 & 0.0009 & 0.0303 \\
\hline
\end{tabular}




\section{Table 14: "Who Wins" within Married Couples and Employment Status of Spouses - Ordered Probit regressions results}

This table reports the results of ordered probit regressions estimated with robust standard errors and time fixed effects (years). Period: 1 January 2011 - 31 December 2016. The dependent variable is a score variable which takes values $-1,0$ and 1 according to whether the absolute ATR adjustment of the wife is greater than (winning husband), equal to (no winner), or smaller than (winning wife) the absolute ATR adjustment of her husband. Riskier Wife is a binary variable equal to 1 when the Calculated ATR of the wife is greater than the Calculated ATR of her husband. Riskier Husband is a binary variable equal to 1 when the Calculated ATR of the husband is greater than the Calculated ATR of his wife. Employment Rank is the simple average of the employment ranks of the spouses. The individual employment rank is computed as a score variable which takes the value 2 when the spouse works as a "Director or Partner", 0 when the spouse is "Non-Working", and 1 otherwise. Employment Rank Spread (F-M) is the difference between the employment rank of the wife and her husband. Other variables are measured as simple averages across the two spouses of the values of the variables. Definitions and measurements are explained in the notes to Table 2. Z-tests are reported in parentheses. Marginal effects are reported in percentages. $*, * *$ and $* * *$ indicate significance at the $10 \%, 5 \%$ and $1 \%$ levels respectively.

\begin{tabular}{|c|c|c|c|c|c|}
\hline \multirow{2}{*}{ Dep.Var. } & \multicolumn{5}{|c|}{ Winning Wife $\{-1,0,+1\}$} \\
\hline & (1) & (2) & (3) & (4) & (5) \\
\hline \multicolumn{6}{|l|}{ Ind. Variables: } \\
\hline \multirow[t]{2}{*}{ Age } & $\begin{array}{c}0.0093^{* *} \\
(2.47)\end{array}$ & $\begin{array}{c}0.0097^{* * *} \\
(2.61)\end{array}$ & & & $\begin{array}{c}0.0096^{* * *} \\
(2.59)\end{array}$ \\
\hline & $0.042 \%$ & $0.049 \%$ & & & $0.049 \%$ \\
\hline \multirow[t]{2}{*}{$\mathrm{Age}^{2}$} & $-0.0603 * *$ & $-0.0614^{* *}$ & & & $-0.0607 * *$ \\
\hline & $\begin{array}{c}(-2.01) \\
-\end{array}$ & $\begin{array}{c}(-2.07) \\
-\end{array}$ & & & $\begin{array}{c}(-2.05) \\
-\end{array}$ \\
\hline \multirow[t]{3}{*}{10 Question Questionnaire } & 0.0036 & $0.0174^{*}$ & & & $0.0177^{*}$ \\
\hline & $(0.36)$ & $(1.79)$ & & & (1.82) \\
\hline & $0.081 \%$ & $0.394 \%$ & & & $0.400 \%$ \\
\hline \multirow[t]{3}{*}{ Capacity } & $0.0560 * * *$ & $0.0465^{* * *}$ & & & $0.0470 * * *$ \\
\hline & (3.45) & $(2.91)$ & & & (2.94) \\
\hline & $1.082 \%$ & $0.810 \%$ & & & $0.826 \%$ \\
\hline \multirow[t]{3}{*}{ Time } & -0.0092 & -0.0085 & & & -0.0081 \\
\hline & $(-0.69)$ & $(-0.64)$ & & & $(-0.61)$ \\
\hline & $-0.346 \%$ & $-0.378 \%$ & & & $-0.362 \%$ \\
\hline \multirow[t]{3}{*}{ Liquidity } & 0.0109 & 0.0086 & & & 0.0086 \\
\hline & $(1.00)$ & $(0.81)$ & & & $(0.80)$ \\
\hline & $0.153 \%$ & $0.071 \%$ & & & $0.073 \%$ \\
\hline \multirow[t]{3}{*}{ Capacity*Time*Liquidity } & -0.0042 & -0.0056 & & & -0.0054 \\
\hline & $(-0.60)$ & $(-0.81)$ & & & $(-0.79)$ \\
\hline & - & - & & & - \\
\hline \multirow[t]{3}{*}{ Riskier Wife } & & $-0.7357 * * *$ & & & $-0.7356 * * *$ \\
\hline & & $(-25.59)$ & & & $(-25.58)$ \\
\hline & & $-16.653 \%$ & & & $-16.606 \%$ \\
\hline \multirow[t]{3}{*}{ Riskier Husband } & & $0.2608 * * *$ & & & $0.2610 * * *$ \\
\hline & & $(16.36)$ & & & $(16.38)$ \\
\hline & & $5.904 \%$ & & & $5.893 \%$ \\
\hline \multirow[t]{3}{*}{ Employment Rank } & & & $-0.1186 *$ & $-0.1051^{*}$ & $-0.1171 *$ \\
\hline & & & $(-1.88)$ & $(-1.67)$ & $(-1.86)$ \\
\hline & & & $-2.652 \%$ & $-2.345 \%$ & $-2.644 \%$ \\
\hline \multirow[t]{3}{*}{ Employment Rank Spread (F-M) } & & & 0.0416 & $0.1460 * *$ & $0.1581 * * *$ \\
\hline & & & $(1.06)$ & $(2.57)$ & $(2.88)$ \\
\hline & & & $0.931 \%$ & $3.182 \%$ & $3.498 \%$ \\
\hline \multirow[t]{3}{*}{ Employment Rank Spread (F-M) ${ }^{2}$} & & & & $0.1160 * *$ & $0.1116 * *$ \\
\hline & & & & $(2.50)$ & $(2.56)$ \\
\hline & & & & - & - \\
\hline Observations & 58,530 & 58,530 & 58,530 & 58,530 & 58,530 \\
\hline Time FE (Year) & Y & Y & Y & Y & Y \\
\hline Pseudo $\mathrm{R}^{2}$ & 0.0009 & 0.0303 & 0.0004 & 0.0004 & 0.0305 \\
\hline
\end{tabular}




\section{Table 15: "Who Wins" within Married Couples and Investment Experience of Spouses - Ordered Probit regressions results}

This table reports the results of ordered probit regressions estimated with robust standard errors and time fixed effects (years). Period: 1 January 2011 - 31 December 2016. The dependent variable is a score variable which takes values $-1,0$ and 1 according to whether the absolute ATR adjustment of the wife is greater than (winning husband), equal to (no winner), or smaller than (winning wife) the absolute ATR adjustment of her husband. Riskier Wife is a binary variable equal to 1 when the Calculated ATR of the wife is greater than the Calculated ATR of her husband. Riskier Husband is a binary variable equal to 1 when the Calculated ATR of the husband is greater than the Calculated ATR of his wife. Investment Experience is the average investment experience of the couple. The investment experience for each spouse is the investor's level of experience in investing and is measured as an integer score variable (0-2) according to whether he/she is not experienced and has no financial knowledge, whether he/she has a medium level of experience and financial literacy, or whether he/she is comfortable in investing and understands potential financial risks and rewards. Investment Experience Spread (F-M) is the difference between the investment experience of the wife and her husband. Other variables are measured as simple averages of the values across the two spouses. Definitions and measurements are explained in the notes to Table 2. Z-tests are reported in parentheses. Marginal effects are reported in percentages. $*, * *$ and $* * *$ indicate significance at the $10 \%, 5 \%$ and $1 \%$ levels respectively.

\begin{tabular}{|c|c|c|c|c|c|}
\hline \multirow{2}{*}{ Dep.Var. } & \multicolumn{5}{|c|}{ Winning Wife $\{-1,0,+1\}$} \\
\hline & (1) & $(2)$ & (3) & (4) & (5) \\
\hline \multicolumn{6}{|l|}{ Ind. Variables: } \\
\hline \multirow[t]{3}{*}{ Age } & $0.0445^{* * *}$ & $0.036 * *$ & & & $0.0338 * *$ \\
\hline & $(2.87)$ & $(2.28)$ & & & $(2.14)$ \\
\hline & $-0.021 \%$ & $0.010 \%$ & & & $-0.001 \%$ \\
\hline \multirow[t]{3}{*}{ Age $^{2}$} & -0.3643 & -0.2852 & & & -0.2714 \\
\hline & $(-2.95)$ & $(-2.29)$ & & & $(-2.18)$ \\
\hline & - & - & & & - \\
\hline \multirow[t]{3}{*}{10 Question Questionnaire } & 0.0476 & $0.0746 * *$ & & & $0.0749 * *$ \\
\hline & $(1.24)$ & $(2.04)$ & & & $(2.05)$ \\
\hline & $1.106 \%$ & $1.706 \%$ & & & $1.709 \%$ \\
\hline \multirow[t]{3}{*}{ Capacity } & 0.046 & 0.0077 & & & -0.0098 \\
\hline & $(0.69)$ & $(0.12)$ & & & $(-0.15)$ \\
\hline & $1.359 \%$ & $0.978 \%$ & & & $0.692 \%$ \\
\hline \multirow[t]{3}{*}{ Time } & 0.0083 & -0.0034 & & & -0.009 \\
\hline & $(0.15)$ & $(-0.06)$ & & & $(-0.16)$ \\
\hline & $0.415 \%$ & $0.532 \%$ & & & $0.491 \%$ \\
\hline \multirow[t]{3}{*}{ Liquidity } & 0.0051 & -0.0206 & & & -0.0316 \\
\hline & $(0.11)$ & $(-0.46)$ & & & $(-0.70)$ \\
\hline & $0.268 \%$ & $-0.059 \%$ & & & $-0.248 \%$ \\
\hline \multirow[t]{2}{*}{ Capacity*Time*Liquidity } & 0.0063 & 0.0176 & & & 0.0202 \\
\hline & $(0.22)$ & $(0.64)$ & & & $(0.73)$ \\
\hline \multirow[t]{3}{*}{ Riskier Wife } & & $-0.9209 * * *$ & & $-0.9270 * * *$ & $-0.9271 * * *$ \\
\hline & & $(-7.73)$ & & $(-7.75)$ & $(-7.75)$ \\
\hline & & $-21.057 \%$ & & $-20.502 \%$ & $-21.145 \%$ \\
\hline \multirow[t]{3}{*}{ Riskier Husband } & & $0.6024 * * *$ & & $0.6408 * * *$ & $0.6415^{* * *}$ \\
\hline & & (9.14) & & (9.51) & $(9.50)$ \\
\hline & & $13.775 \%$ & & $14.173 \%$ & $14.632 \%$ \\
\hline \multirow[t]{3}{*}{ Investment Experience } & & & $0.0799 * *$ & $0.079 * *$ & $0.073 * *$ \\
\hline & & & $(2.23)$ & $(2.34)$ & $(2.01)$ \\
\hline & & & $1.781 \%$ & $1.747 \%$ & $1.665 \%$ \\
\hline \multirow[t]{3}{*}{ Investment Experience (F-M) } & & & $-0.0999 * *$ & $0.1138 * *$ & $0.1133^{* *}$ \\
\hline & & & $(-2.00)$ & $(2.29)$ & $(2.29)$ \\
\hline & & & $-2.228 \%$ & $2.517 \%$ & $2.583 \%$ \\
\hline Observations & 3,999 & 3,999 & 3,999 & 3,999 & 3,999 \\
\hline Time FE (Year) & Y & $\mathrm{Y}$ & Y & $\mathrm{Y}$ & Y \\
\hline Pseudo $\mathrm{R}^{2}$ & 0.00232 & 0.0772 & 0.00238 & 0.0777 & 0.0794 \\
\hline
\end{tabular}

